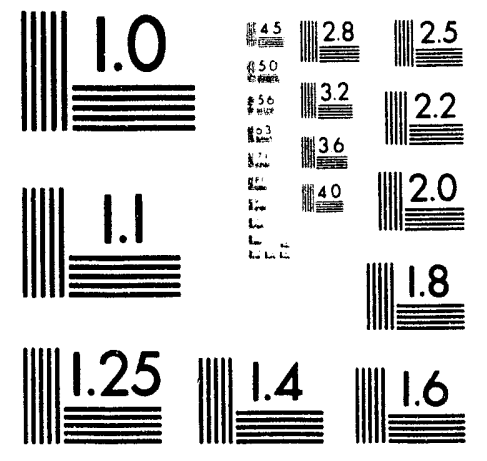



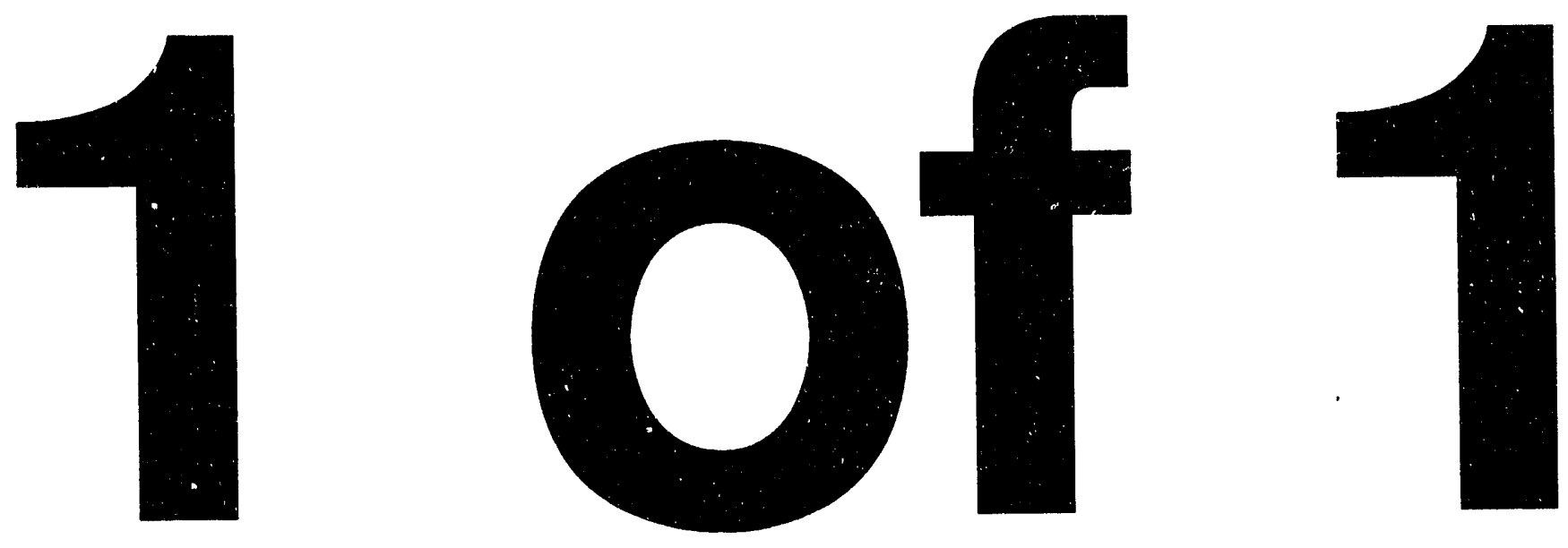


\section{PROBABILITY COMPUTATIONS USING THE SIGMA-PI METHOD ON A PERSONAL COMPUTER}

by
F. Eric Haskin, Maximo S. Lazo, and A. Sharif Heger Department of Chemical and Nuclear Engineering University of New Mexico

September 31,1990

\section{INTRODUCTION}

2 INSTALLATION AND TESTING OF VAX VERSION OF SIGPI

3 DEVELOPMENT AND TESTING OF PC VERSION OF SIGPI . . . . . . 6

3.1 DEVELOPMCNT OF VERSION UNM-B . . . . . . . . . . . . . 6

FORTRAN Compilers ...................... . . 6

Boolean operations ..................... . . 7

Transfers into IF Blocks . . . . . . . . . . . . . 7

Opening/Closing Files (Character Increment) . . . . . . . . . 8

Machine Specific Constants . . . . . . . . . . . . . . 8

3.2 TESTING OF VERSION UNM-B . . . . . . . . . . . . . . . . . . . . . . . 9

3.3 FUTURE TASKS $\ldots \ldots \ldots$

Multiple Probability Sets . . . . . . . . . . . . . . . . 10

Problems with Dependencies . . . . . . . . . . . . . . . . 10

Common Blocks Mismatched . . . . . . . . . . . . . . . . 10

Optimal Linkage ........................ 11

4 SIGPI LIMITATIONS AND POTENTIAL ENHANCEMENTS . . . . . . . 12

4.1 RESTRICTION TO GAUSSIAN DISTRIBUTIONS FOR DEPENDENT EVENTS . . . . . 12

4.2 EASE OF INPUT PREPARATION . . . . . . . . . . . . . . . . . . . . . . 13

4.3 ALTERNATIVE LOWER BOUND $\ldots \ldots$

4.4 SENSITIVITY/UNCERTAINTY ANALYSIS CAPABILITY . . . . . . . . . . . 16

5 CONCLIISIONS AND RECOMMENDATIONS $\ldots \ldots \ldots$

REFERENCES ......................... 19

APPENDICES ......................... . . 20

A. CONVERT PROGRAM . . . . . . . . . . . . . . . . . . . 20

B. DESCRIPTION OF TEST RUNS 5,6 , AND 7 . . . . . . . . . . . . . . 21

C. HAND CALCULATION FOR TEST RUN $6 \ldots \ldots$. . . . . . . . . . . . . . . . 23

D. PROOF OF ALTERNATIVE LOWER BOUND $\ldots \ldots$

E. SIGPI CALL TREE $\ldots \ldots \ldots$

\section{DISCLAIMER}

This report was prepared as an account of work sponsored by an agency of the United States Government. Neither the United States Gnvernment nor any agency thereof, nor any of their employees, makes any warranty, express or implied, or assumes any legal liability or responsibility for the accuracy, completeness, or usefulness of any information, apparatus, product, or process disclosed, or represents that its use would not infringe privately owned rights. Reference herein to any specific commercial product, process, or service by trade name, trademark, manufacturer, or otherwise does not necessarily constitute or imply its endorsement, recommendation, or favoring by the United States Government or any agency thereof. The views and opinions of authors expressed herein do not necessarily state or reflect those of the United States Government or any agency thereof. 


\section{ABSTRACT}

The SIGMA-PI ( $\Sigma \Pi)$ method as implemented in the SIGPI computer code, is designed to accurately and efficiently evaluate the probability of Boolean expressions in disjunctive normal form given the base event probabilities. The method is not limited to problems in which base event probabilities are small, nor to Boolean expressions that exclude the compliments of base events, nor to problems in which base events are independent. The feasibility of implementing the $\Sigma$ method on a personal computer has been evaluated, and a version of the SIGPI code capable of quantifying simple Boolean expressions with independent base events on the personal computer has been developed. Tasks required for a fully functional personal computer version of SIGPI have been identified together with enhancements that could be implemented to improve the utility and efficiency of the code. 


\section{INTRODUCTION}

In July, 1990, Los Alamos National Laboratory Division N-6 contracted with the University of New Mexico (UNM) Department of Chemical and Nuclear Engineering to develop a personal computer (PC) version of the SIGPI computer code. The results of the UNM effort to date are presented in this report.

The SIGMA-PI ( $\Sigma \Pi$ ) method as implemented in the SIGPI computer code, is a method for accurately and efficiently evaluating the probability of a Boolean expressions in disjunctive normal form (top events) when the base event probabilities are specified via user input. Untike other top event quantification codes, SIGPI is not limited to problems in which base event probabilities are small, nor to Boolean expressions that exclude the compliments of base events, nor to problems in which base events are independent (although SIGPI requires dependent events be normally distributed).

It is beyond the scope of this report to discuss the $\Sigma$ m method or the SIGPI computer code in detail. The reader is presumed to be familiar with the descriptions provided in References 1 and 2.

A decision was made to conduct the UNM project by a) assuming a PC version ould be developed and b) initiating the development process. The process followed is depicted in Figure 1 and discussed in detail in this report. To date the process has yielded PC Version UNM-B of SIGPI, which successfully runs the simpler SIGPI test problems. Conclusions and recommendations regarding further developmental efforts are discussed in Section 5 . 


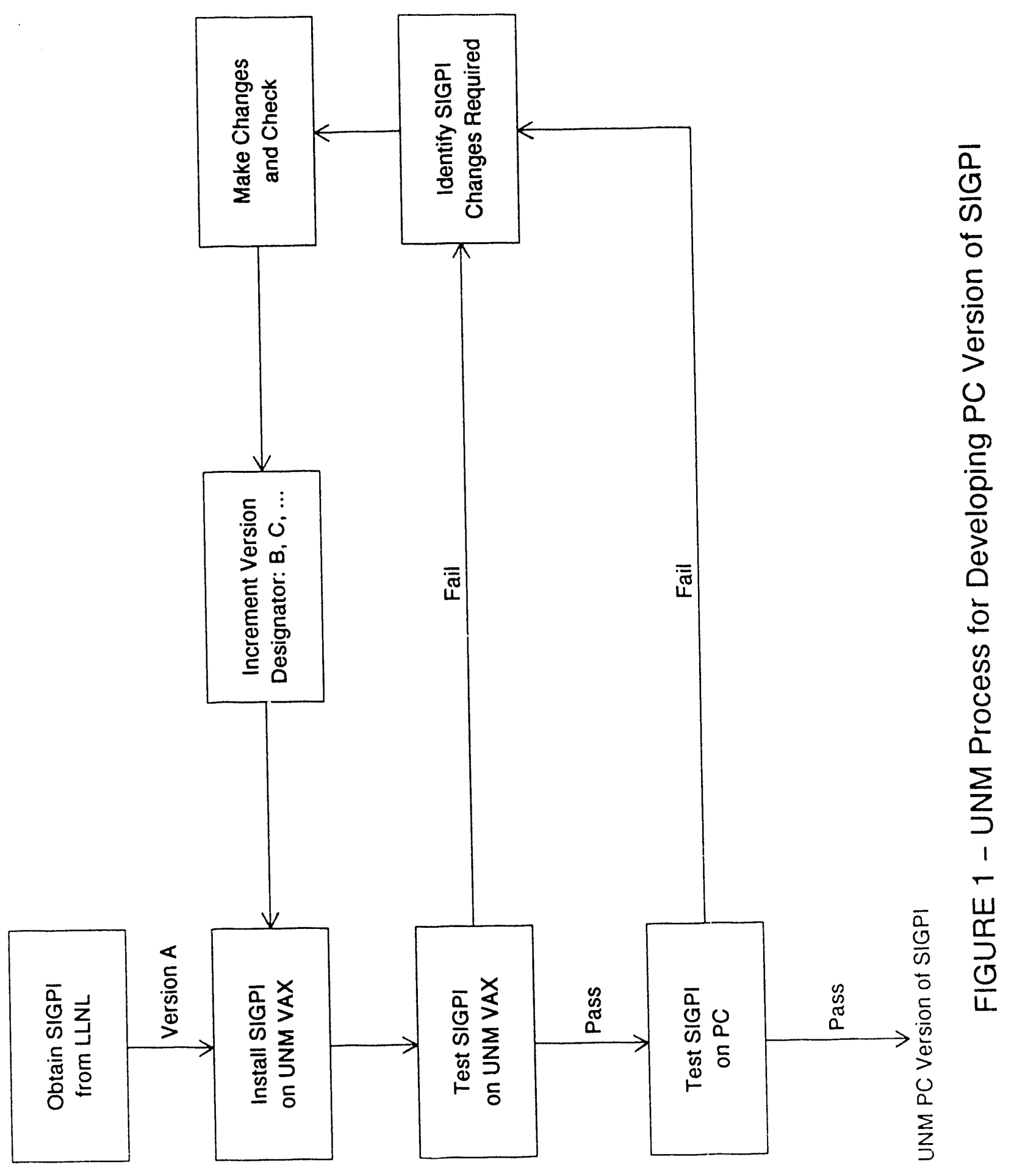




\section{INSTALLATION AND TESTING OF VAX VERSION OF SIGPI}

The VAX version of SIGPI and copies of References 1 and 2 were obtained from Cherie Jo Patenaude of Lawrence Livermore National Laboratory (LLNL). Ms. Patenaude is the original programmer of SIGPI.[2] SIGPI was installed on the UNM VAX system and compiled without error. However, in order to get the sample problems to run, the LLNL CFTAP program' had to be modified to convert ASCII cut set input files to the binary (unformatted in FORTRAN) form required by SIGPI. A listing of the modified program, named CONVERT is included as Appendix A. In addition, a timing routine was added to calculate run times, and a subroutine call tree was generated (see Appendix E).

All of the test runs from the SIGPI User's Manual [1] were run successfully on the UNM VAX. These test runs are based on four top event files: TEST1, TEST2, TEST3, and TEST4 1 isted in the SIGPI User's Manual. Three additional test runs were devised based on the following three additional top event expressions:

TEST5 - Corresponds to the example shown in Figure 3.8 of Reference 1 (probability file PTEST5),

TEST6 - Corresponds to the example shown in Figure 9 of the SIGPI User's Manual [2] (probability file PTEST6),

TEST7 - Corresponds to example problem in TEMAC User's Manual [3] (probability file PTEST7).

Listings of the SIGPI input for these three additional test runs are included as Appendix B.

'The CFTAP program, also obtained from Ms. Patenaude converts a file in FTAP format to SIGPI cut set and probability files. 
Figure 2 summarizes many features (number of cut sets, number of base and compliment events appearing in the top event expression, number of independent events, and number of dependent events) for the seven top event expressions. It also presents the test results obtained from the original VAX version (version UNM-A) of SIGPI for a11 of the test runs. Note that the upper bounds predicted for Cases $3 \mathrm{~B} 2$ and $3 \mathrm{~B} 3$, were closer to the lower bound than listed in the User's Manual. This is apparently attributable to changes made at LLNL subsequent to the User's Manual. Note also that the run times increase with the size of the problem, and with the introduction of dependencies. The run times actualiy decrease slightly as compliment events are introduced, apparently because this speeds the SIGPI decomposition process. For Test 6, which corresponds to Figure 9 of the User's Manual, no reference quantification was available; therefore, a hand calculation was performed and is included as Appendix $C$. The SIGPI version UNM-A result 1 isted in Figure 2 (approximately 0.597 ) was found to be slightly below the result calculated in Appendix $C(0.613)$. The reason for the discrepancy has not yet been determined. Test 7 corresponds to the sample problem in the TEMAC User's Manual [3]. The difference between the TEMAC result $\left(0.234 \times 10^{-7}\right)$ and that obtained using SIGPI $\left(0.2194 \times 10^{-7}\right)$ may be attributable to the fact that TEMAC assumes the validity of the small event approximation for the union of cut sets. 


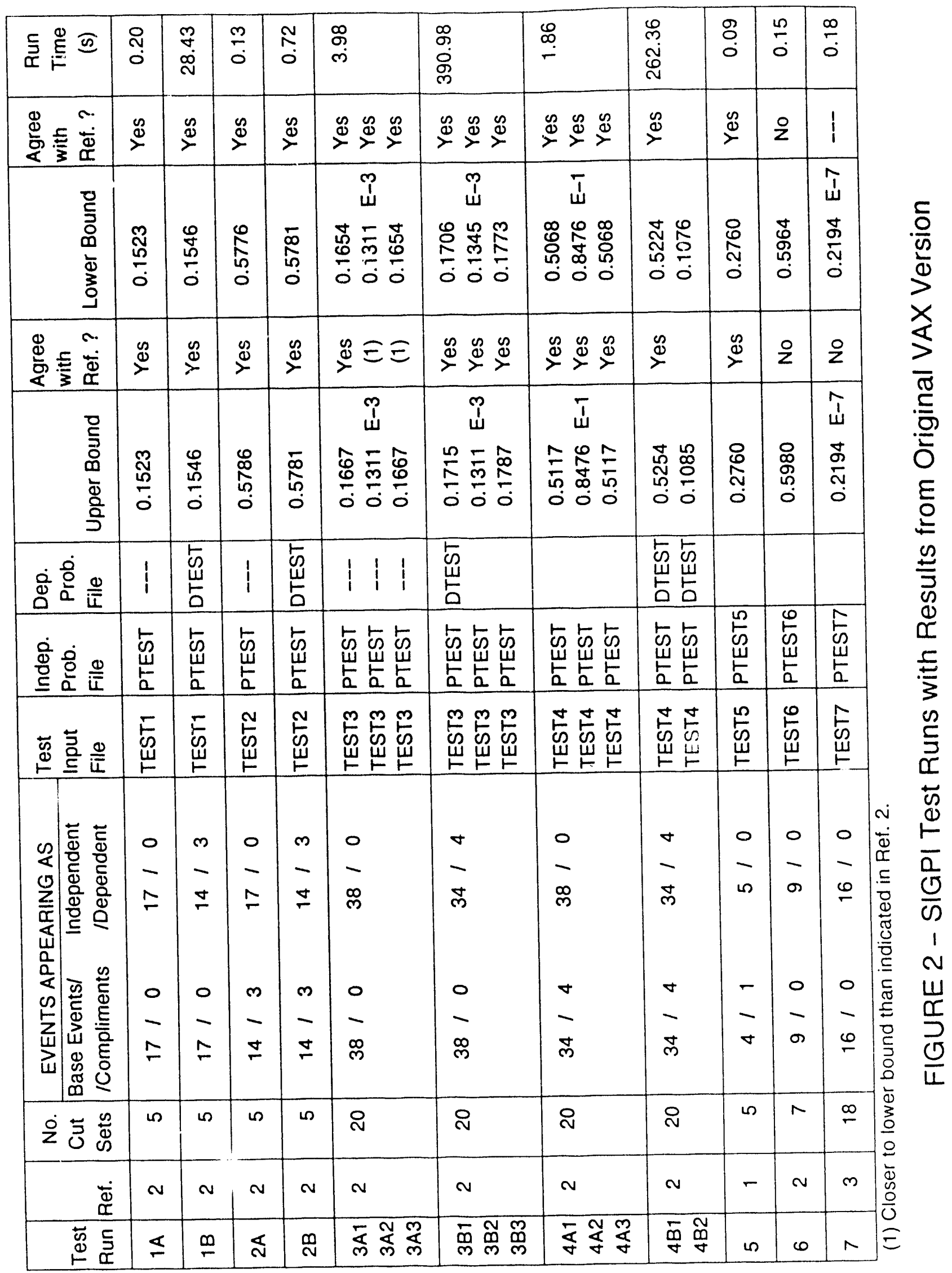




\section{DEVELOPMENT AND TESTING OF PC VERSION OF SIGPI}

\subsection{DEVELOPMENT OF VERSION UNM-B}

\section{FORTRAN CompiTers}

Two FORTRAN compilers that are widely used for PC applications were available for this project. Lahey FORTRAN is capable of utilizing extended memory for $386 \mathrm{PC}^{\prime} \mathrm{S}$ operating under DOS (Version 3.0 or above). Microsoft FORTRAN is not canable of utilizing extended or expanded memory under DOS; however, Microsoft has a version of their FORTRAN that will run with IBM's Operating System $2(0 S / 2)$, which does not have the 640K RAM limitation associated with DOS.

The PC provided by LANL for UNM to use on this project is an IBM Personal System 2, Model 70 with 6 MB of memory and a DOS 3.3 operating system. Although $0 S / 2$ could be installed on this machine, a decision was made to retain DOS and use Lahey FORTRAN, at least for the initial UNM efforts described in this report. It was determined that the changes required to get SIGPI to compile in Lahey FORTRAN would also be compatible with Microsoft FORTRAN. Fewer changes would have been required for Microsoft FORTRAN because it accepts the Boolean operations on integer variables contained in the original VAX version of SIGPI; however, the resulting version would not be compatible with Lahey FORTRAN. The DOS/Lahey approach is consistent with the intent to develop as portable a version of SIGPI as possible. Specifically the objective is that (except for machine specific constants) the PC version of SIGPI should compile without fatal errors, link and run using VMS/VAX FORTRAN, DOS/Lahey FORTRAN, or Microsoft FORTRAN. The coding changes initially identified as being required to meet this objective fell into four areas as discussed in the following subsections. SIGPI with these changes now exists as version UNM-B. 


\section{Boolean Operations}

SIGPI declares all variables INTEGER by default through an IMPLICIT INTEGER (A-Z) statement. Non-integer variables are declared through the use of REAL, LOGICAL, or CHARACTER statements.

The vast majority of SIGPI FUNCTIONS and SUBROUTINES have Boolean operations of the form

$$
\begin{aligned}
& I 1=I A \cdot A N D \cdot I B \\
& I 2=I A \cdot O R \cdot I B \\
& I 3=\text { NOT.IA } \\
& I 4=I A \cdot X O R \cdot I B
\end{aligned}
$$

where IA, IB, I1, I2, I3, and I4 arz integer variables. Although VAX and Microsoft FORTRAN compilers permit these usages, Lahey FORTRAN does not. As a result it was necessary to change the preceding forms to

$$
\begin{aligned}
& I 1=\operatorname{IAND}(I A, I B) \\
& I 2=\operatorname{IOR}(I A, I B) \\
& I 3=\operatorname{NOT}(I A) \\
& I 4=I E O R(I A, I B) .
\end{aligned}
$$

These forms are supported by all three compilers: Lahey, Microsoft, and VAX. An estimated 350 lines of FORTRAN had to be changed in the original VAX version of SIGPI to accomplish this task.

\section{Transfers into IF Blocks}

In four locations, the original version of SIGPI had GO TO statements outside an IF, THEN, ENDIF block that transferred the program to a numbered statement between the THEN and ENDIF. Such constructions are not acceptable in Lahey FORTRAN. A typical example of a modification to this type of structure is presented below. 
Original Version

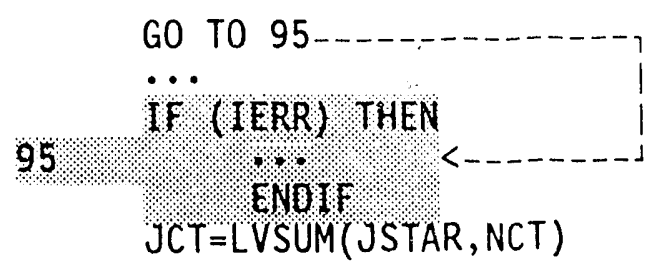

Modified Version

$\begin{array}{ll} & \text { GO TO } 95 \\ & \ldots \\ 95 & \text { IF (.NOT. IERR) GOTO } 96 \\ 96 & \text { CONTINUE } \\ & \text { JCT }=\text { LUSUM(JSTAR, NCT) }\end{array}$

Opening/Closing Files (Character Increment)

The SIGPI subroutine ADDONE increments an ASCII file name by one ASCII character. For example, file name TEMPAAAA becomes TEMPAAAB. The scheme used in the original version of SIGPI was not portable and would not compile in Lahey FORTRAN. The subroutine was rewritten to make it portable.

\section{Machine Specific Constants}

The SIGPI subroutine DMACH1 is used to return double precision machine dependent constants. The following table summarizes the machine dependent constants used in the VAX and PC (see Ref. 6):

Constant Interpretation

$\operatorname{DIMACH}(1)=B^{\star \star}(E M I N-1)$, the smallest positive magnitude

$\operatorname{DIMACH}(2)=B^{\star} E M A X *\left(1-B^{\star *}(-T)\right)$, the largest magnitude

$\operatorname{DIMACH}(3)=B^{* *}(-T)$, the smallest relative spacing

$\operatorname{DIMACH}(4)=B^{\star \star}(1-T)$, the largest relative spacing

$\operatorname{DIMACH}(5)=\operatorname{LOGIO}(B)$

VAX Value

DIMACH (1)
DIMACH (2)
DIMACH (3)
DIMACH (4)
DIMACH (5)

$2.9387358770557188 \mathrm{E}-39$

$1.7014118346046923 E+38$

$1.3877787807814457 \mathrm{E}-17$

$2.7755575615628914 \mathrm{E}-17$

0.3010299956639812
PC Value

$2.230-308$

$1.790+308$

1. $110-16$

2.220-16

0.30102999566398119500 


\subsection{TESTING OF VERSION UNM-B}

As indicated above, the FORTRAN changes made in developing SIGPI version UNR-B are compatible with Lahey, Microsoft, and VAX FORTRAN compilers. The coding changes were verified in two ways. First, a listing of all differences between the original VAX version (UNM-A) and version UNM-B was obtained and checked. This revealed a few errors, which were easily fixed. Next, version UNM-B was compiled, linked, and run on the VAX. The upper and lower bounds obtained for the eleven test runs were the same as presented in Table 1; however, for runs involving more than one set of probabilities (test runs $3 A, 3 B, 4 A$, and $4 B$ ), version $U N M-B$ ran only the first case. The cause of this difficulty is currently under investigation. Other than slight timing changes, which are small compared to the accuracy of the timing routine, no other differences were found between the results obtained using version UNM-A and those obtained using the version UNM-B on the VAX.

After performing a line by line check of all UNM-originated changes and verifying that the test problems ran using version UNM-B on the VAX, version UNM-B was compiled and linked and the test problems were run on the PS/2 Model 70. The PC results for test runs $1,2,5,6$, and 7 are identical to the VAX results (see figure 2). These test runs are relatively simple, in particular they involve no dependent events. The PC results (upper and lower bounds) for test runs $3 A 1$ and $4 B 1$ (larger problems but without dependent events) are slightly less than the corresponding VAX results indicated in Figure 2. The reason for these differences is currently being investigated. Finally, the $P C$ results for test runs $1 B, 2 B, 3 B$, and $4 B$, which involve dependent events, failed to execute properly on the PC. The reason for such failures has not yet been determined. The quantitative $P C$ results obtained with version UNM-B are tabulated below. 


$\begin{array}{lllr}\begin{array}{l}\text { Test } \\ \text { Run }\end{array} & \begin{array}{l}\text { Upper } \\ \text { Bound }\end{array} & \begin{array}{l}\text { Lower } \\ \text { Bound }\end{array} & \begin{array}{l}\text { Run } \\ \text { Time } \\ (\mathrm{s})\end{array} \\ \text { 1A } & 0.1523 & 0.1523 & 0.05 \\ 2 A & 0.5786 & 0.5786 & 0.06 \\ 3 A 1 & 0.1613 & 0.1601 & 10.88 \\ 4 A 1 & 0.5010 & 0.4993 & 5.11 \\ 5 & 0.2760 & 0.2760 & 0.05 \\ 6 & 0.5980 & 0.5964 & 0.06 \\ 7 & 0.2194 \mathrm{E}-7 & 0.2194 \mathrm{E}-7 & 0.11\end{array}$

\subsection{FUTURE TASKS}

\section{Multiple Probability Sets}

When the test runs were made using version UNM-B (see Section 3.2) those test runs involving multiple sets of input probabilities ran only for the first set. At the time of this report, the cause for this failure to process multiple input sets had not been determined.

\section{Problems with Dependencies}

When the test runs were made on the PC using version UNM-B (see Section 3.2) those test runs involving dependent events failed to execute properly. At the time of this report, the cause for this failure has not been determined.

\section{Common Blocks Mismatched}

Compilation of SIGPI version UNM-B using Lahey FORTRAN on the PC revealed that the original SIGPI COMMON blocks are not matched in size from subroutine to subroutine.

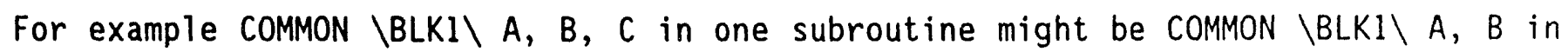
another subroutine. However, the mismatched common blocks apparently' caused no problems in running on the VAX, and they seem unlikely to be the cause of problems ericountered with the PC test runs. 


\section{Optimal Linkage}

The size of the executable file for the PC version of SIGPI, as generated by Lahey FURTRAN without optimization, is approximately $1 \mathrm{MB}$ and the memory requirement is approximately 2.3 MB. Lahey FORTRAN has an compilation option that is designed to reduce the size of the executable file. This option could be investigated in the future (see Section 5). 


\section{SIGPI LIMITATIONS AND POTENTIAL ENHANCEMENTS}

In the process of becoming familiar with the $\Sigma \pi$ method and the SIGPI computer code, four areas were identified in which SIGPI has limitations that could be remedied either by modifications to the SIGPI code or by developing interfaces between SIGPI and other well established codes. These SIGPI limitations and potential enhancements are discussed in this section.

\subsection{RESTRICTION TO GAUSSIAN DISTRIBUTIONS FOR DEPENDENT EVENTS}

The probabilities of dependent events are currently calculated in SIGPI by integrating over user-specified Gaussian (norma1) distributions. Dependencies are introduced via a user-supplied covariance matrix. Probabilities of the intersections of two or more dependent events are also calculated by integrating over the multivariate Gaussian distribution as indicated in the equations on page 10 of the User's Manual [2]. A reasonable option to this approach, at least for the limited number of dependencies currently allowed in SIGPI, would be to specify the probabilities of all potential intersections of dependent events directly via user input. This would allow alternative methods for modeling multivariate probability structures to be used external to SIGPI. For example the Latin Hypercube Sampling approach [5] can accommodate a wide variety of marginal distribution types and will permit rank correlations. To illustrate, for test runs $3 B$ and $4 B$, there are four dependent events: call them $A, B, C$, and $D$. The most information SIGPI could possibly require regarding dependent probabilities would be $P(A \cap B), P(A \cap C), P(A \cap D), P(B \cap C), P(B \cap D), P\left(C_{n} D\right)$, $P(A \cap B \cap C), P(A \cap B \cap D), P(A \cap C \cap D), P(B \cap C \cap D)$, and $P(A \cap B \cap C \cap D)$. Alternatively, one could to specify the dependent data via conditional probabilities: $P(A \mid B), P(A \mid C), P(A \mid D)$, etc. (see also Section 4.3 ). 


\subsection{EASE OF INPUT PREPARATION}

The minimal cut sets that are defined via SIGPI input files are usually generated by codes such as SETS [4] that reduce Boolean expressions (e.g. fault trees logic) to disjunctive normal form. Disjunctive normal output files from codes such as SETS cannot currently be used as input files for SIGPI. Consequently, output from SETS or similar codes must be manually converted to the format read by SIGPI. To circumvent this limitation, a stand-alone preprocessor (e.g., SETS-to-SIGPI) could be written, and, if warranted by high usage, incorporated into SIGPI. ${ }^{2}$

\subsection{ALTERNATIVE LOWER BOUND}

The upper bounds on the probabilities calculated by SIGPI are based on the fact that

$$
\rho(\underbrace{m}_{i=1} S_{i}) \leq \sum_{i=1}^{m} \rho\left(S_{i}\right)
$$

where $\rho\left(S_{i}\right)$ denotes the probability of the $i$-th cut set in the current disjunctive normal form. The lower bounds on the probabilities calculated by SIGPI are based on the fact that

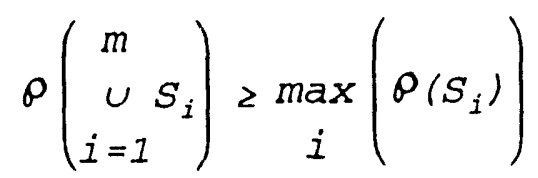

Based on the additive law for non-mutually exclusive events, an alternative lower bound exists (see Appendix D for proof):

\footnotetext{
${ }^{2}$ The LLNL program CFTAP is apparently such a program.
} 


$$
\rho\left({\underset{i=1}{U} S_{i}}_{i}^{m} \geq \sum_{i=1}^{m} P\left(S_{i}\right)-\left(\begin{array}{c}
m \\
2
\end{array}\right) \underset{i}{\max }\left(\rho\left(S_{i}\right)\right) \underset{i, j}{\max }\left(P\left(S_{i} i S_{j}\right)\right)\right.
$$

If the cut sets are independent, which (as explained later) is usually not the case, $P\left(S_{i} \mid S_{j}\right)=P\left(S_{i}\right)$ and this expression reduces to:

$$
\rho\left(\underset{i=1}{\cup} S_{i}\right) \geq \sum_{i=1}^{m} \rho\left(S_{i}\right)-\left(\begin{array}{l}
m \\
2
\end{array}\right)\left(\max _{i} \rho\left(S_{i}\right)\right)^{2}
$$

When the cut set probabilities are small (that is, when the small probability approximation is applicable), the alternative lower bound is much closer to the true value than the lower bound currently used in SIGPI. This can be demonstrated by considering a simpie problem in which the top event is the union of four independent cut sets each having the same probability; that is,

$$
\begin{gathered}
T E=S_{1} \cup S_{2} \cup S_{3} \cup S_{4} \\
P\left(S_{1}\right)=P\left(S_{2}\right)=P\left(S_{3}\right)=P\left(S_{4}\right)
\end{gathered}
$$

The following table compares the two lower bounds for this problem:

\begin{tabular}{l} 
Current \\
Lower \\
Bound \\
\hline
\end{tabular}

1

0.9

0.8

0.7

0.66667

0.6

0.5

0.4

0.3

0.2

0.1

0.01
Alternative
Lower
Bound

$-2$

$-1.26$

$-0.64$

$-0.14$

0

0.24

0.50

0.64

0.66

0.56

0.34

0.0394
Exact

Probability

1

0.9999

0.9984

0.9919

0.9877

0.9744

0.9375

0.8704

0.7599

0.5904

0.3439

0.039403

As indicated in the table, the alternative lower bound is much closer to the true value when the cut set probabilities are small. However, when large probabilities are 
involved, the current SIGPI lower bound should clearly be used. One approach would be to combine the two as follows:

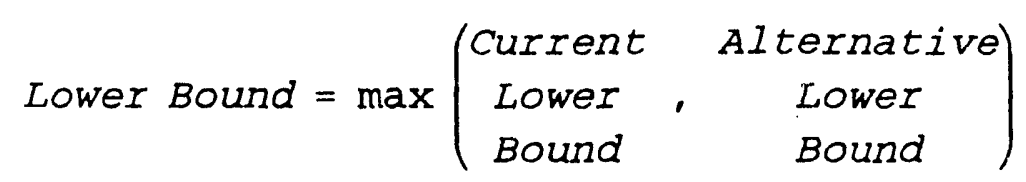

Note that the alternative lower bound requires the conditional probabilities $\rho\left(S_{i} \mid S_{j}\right)$ be known for all pairs of cut sets at the current decomposition level. Any two cut sets $S_{i}$ and $S_{j}$ that share one or more base events are neither independent, $P\left(S_{i} \mid S_{j}\right) \neq P\left(S_{i}\right)$, nor mutually exclusive, $P\left(S_{i} \mid S_{j}\right) \neq 0$. For example, if $A, B, C, D$, and E denote base events and

$$
\begin{aligned}
& S_{1}=A \cap B \cap C \\
& S_{2}=C \cap D \cap E
\end{aligned}
$$

then

$$
\begin{aligned}
& P\left(S_{1} \mid S_{2}\right)=P(A \cap B), \\
& P\left(S_{2} \mid S_{1}\right)=P(D \cap E) .
\end{aligned}
$$

If the base events are independent the computation is based on the multiplicative law for independent events:

$$
P(A \cap B \cap \cdots \cap Z)=P(A) P(B) \cdots P(Z)
$$

If the two or more of the base events are dependent, integration over the joint Gaussian probability distribution is involved. Therefore, to implement the alternative lower bound in SIGPI as suggested above would require the conditional probabilities $P\left(S_{i} \mid S_{j}\right)$ be computed for each SIGPI subproblem at each decomposition level. Of course, at the end of the SIGPI decomposition process $\rho\left(S_{i} \mid S_{j}\right)=0$, that is, all cut sets are disjoint and the lower and upper bound expressions presented above reduce to the additive law for mutually exclusive events. 


\subsection{SENSITIVITY/UNCERTAINTY ANALYSIS CAPABILITY}

SIGPI has the capability of quantifying the same top event expression over and over when multiple sets of probabilities are specified via user input. However, there is no capability inherent in SIGPI for analyzing the results of such multiple runs. Specifically sensitivity and uncertainty measures such as partial derivatives, risk increase, risk decrease, and the uncertainty importance measure (see Refs. 3 and 7 ) are not calculated in SIGPI.

For problems involving independent events it would be possible to write a code to interface SIGPI to TEMAC, which could then be used to calculate any of the aforementioned sensitivity and uncertainty measures. This is possible because 1) at each decomposition level SIGPI stores a disjunctive normal form internally, and 2) the equation used to quantify the upper bound probability of the disjunctive normal form at each level is, in essence, the small probability approximation assumed by TEMAC.

For problems involving dependent events, the key question is: "For which input parameters does one want sensitivity and uncertainty measures defined?" Certainly one would want sensitivities with respect to the marginal probabilities; but, for the current version of SIGPI would one want sensitivities with respect to covariances? This question is tied to the options posed in Section 4.2 for expressing dependent probabilities via user input. 


\section{CONCLUSIONS AND RECOMMENDATIONS}

Based on the success achieved to date, the primary conclusion of this report is that a PC version of the SIGPI code is feasible. In fact the existing version UNM-B appears to handle simple problems involving independent base events correctly. The main difficulty encountered to date appears to 1 ie in the routines for evaluating dependent probabilities via integration over the multivariate (joint) Gaussian probability distribution. At the very worst, a PC version of SIGPI in which drpendent probabilities are user-specified could be created, and such a version might prove as useful as the original SIGPI, which is restricted by the assumption of a joint Gaussian distribution for dependent events (see Section 4.2).

Assuming that a decision is made to proceed further with the development of a PC version of SIGPI, it is recommended that the following tasks be undertaken ir the order listed:

1. Debug the UNM-B version to enable the SIGPI capability for processing multiple probability sets (see Section 3.?).

2. Standardize the COMMON blocks (see Section 3.?)

3. Debug the UNM-B version to enable the SIGPI capability for handling Gaussian distributed dependent probabilities (see Section 3.). Note there exists some possibility that this task may prove to be infeasible (see item 6 below).

These tasks would result in a PC version with the same capabilities as the original SIGPI. In addition, the following two tasks are recommended:

4. Resolve the discrepancy between the SIGPI results obtained for Test Run 6 and the results obtained by hand calculation in Appendix $C$.

5. Assure that the PC version of SIGPI compiles and runs in Microsoft FORTRAN.

Four potential enhancements to SIGPI are described in Section 4 of this report in order of their importance as currently perceived by UNM; that is, UNM recommends the following prioritization of SIGPI enhancements from a developmental perspective: 
6. As an input option and/or an alternative should task 3 prove infeasible, add a capability to specify dependent probabilities directly via user input (see Section 4.2)

7. Construct a SETS-to-SIGPI preprocessor to reduce the effort involved in preparing SIGPI input.

8. Investigate the alternative lower bound defined in Section 4.3 further to determine if SIGPI convergence could be accelerated for problems involving small probabilities.

9. Develop a SIGPI-to-TEMAC postprocessor to facilitate sensitivity uncertainty analyses.

It is recognized that others may have different priorities or require different enhancements. UNM cost estimates for performing the tasks listed above (or other SIGPI-related tasks) can be developed upon request.

In principal it would be possible to merge the various quantification codes that are currently being used into a single, comprehensive, yet efficient and user friendly code. Certainly the algorithms exist to accomplish this objective. However, the main reason for undertaking such a project would be to save users' time, consequently, user friendliness and computational efficiency should be carefully considered in the design of any such composite quantification code. The interim approach of improving the effectiveness of existing codes via enhancements and code-to-code interfaces is consistent with this ultimate objective in that it reveals the positive and negative aspects of all codes while maintaining a state-of-the-art capability (if not efficiency). 


\section{REFERENCES}

1. G. C. Corynen, Evaluating the Response of Complex Systems to Environmental Threats: The $\Sigma$ In Method, UCRL-53399, Lawrence Livermore National Laboratory, University of California, Livermore, CA, May 1983.

2. Patenaude, C. J., SIGPI: A User's Manual for Fast Computation of the Prnbabilistic Performance of Complex Systems, NUREG/CR-4800, UCID-20679, Lawrence Livermore National Laboratory, Livermore, CA, September 1986.

3. R. L. Iman and M. J. Shortencarier, A User's Guide for the Top Event Matrix Analysis Code (TEMAC), NUREG/CR-4598, SAND86-0960, Sandia National Laboratories, Albuquerque, NM, August 1986.

4. R. B. Worre11, SETS Reference Manual, NUREG/CR-4213, SAND83-2675, Sandia National Laboratories, Albuquerque, NM, May 1985.

5. R. L. Iman and M. J. Shortencarier, A FORTRAN 77 Program and User's Guide for the Generation of Latin Hypercube and Random Samples for Use With Computer Models, NUREG/CR-3624, SAND83-2365, Sandia National Laboratories, Albuquerque, NM, March 1984 .

6. D. Kahanez, C. Moler, and S. Nash, Numerical Methods and Software, Prentice Hall, 1988.

7. R. L. Iman and S. C. Hora, A Robust Measure of Uncertainty Importance for Use in Fault Tree System Analysis, Risk Analysis, Vol. 10, No. 3, 1990. 


\section{APPENDICES}

\section{APPENDIX A. CONVERT PROGRAM}

The CONVERT program reads a SIGPI user's cut set input file in ASCII format and converts is to binary (unformatted in FORTRAN) form as required by SIGPI.

C

PROGRAM CONVERT

CONVERT DATA FILE TO SEQUENTIAL FILE FOR INPUT TO SIGPI

IMPLICIT INTEGER (A-Z)

DIMENSION SET(80)

CHARACTER $* 16$ IFILE, OFILE, PFILE, OPFILE

CHARACTER $* 8$ DUMMY

CHARACTER $* 8$ NAMES $(1000)$, TNAME

C

$R E A L \star 8 P R O B$

$\operatorname{WRITE}\left(6,{ }^{\prime}(A), \backslash^{\prime}\right)$ ' INPUT CUT SET FILE = '

$\operatorname{RFAD}\left(6, '(A 16)^{\prime}\right)$ IFILE

WRITE $\left(6, '(A), \backslash{ }^{\prime}\right)$ ' OUTPUT CUT SET FILE = '

$\operatorname{READ}\left(6, '(A 16)^{\prime}\right)$ OFILE

OPEN $\left(1, F I L E=\right.$ IFILE, FORM $=$ ' FORMATTED', STATUS $={ }^{\prime}$ OLD' $)$

$\operatorname{OPEN}\left(2, F I L E=O F I L E, F O R M={ }^{\prime}\right.$ UNFORMATTED',$A C C E S S={ }^{\prime}$ SEQUENTIAL',

C

$X$ STATUS $={ }^{\prime}$ UNKNOWN')

C READ NUMBER OF SETS

$\operatorname{WRITE}\left(6,{ }^{*}\right)$ 'NSETS $=$ '

$\operatorname{READ}(5,10)$ NSETS

10 FORMAT(I10)

C READ SETS FOR TOP EVENT

50 DO $1000 I=1$, NSETS

$\operatorname{READ}(1,101) \mathrm{NS},(\operatorname{SET}(N), N=1, N S)$

101 FORMAT (16I5)

WRITE (2) NS
1000 CONTINUE

C

ENDFILE (2)

CLOSE (2)

STOP

END 


\section{APPENDIX B. DESCRIPTION OF TEST RUNS 5, 6, AND 7}

This appendix contain the input data for SIGPI test runs 5, 6, and 7 . The input data for other SIGPI test runs are 1isted in the SIGPI User's Manual [2].

B. 1 Cut Set Data

File TEST5 - Corresponds to the noncoherent problem illustrated in Figures 3.6 and 3.8 of Ref. 1 .

\section{Size Base Events in Set}

$\begin{array}{rrrr}2 & 1 & 2 & \\ 2 & 1 & 5 & \\ 3 & 2 & 3 & 4 \\ 2 & 4 & 5 & \\ 3 & -1 & 2 & 4\end{array}$

File Test6 - Corresponds to the problem depicted in Figure 9 of the User's Manual [2].

Size Base Events in Set

$\begin{array}{llll}3 & 1 & 3 & 4 \\ 3 & 1 & 2 & 4 \\ 3 & 1 & 2 & 3 \\ 3 & 1 & 5 & 7 \\ 3 & 1 & 6 & 7 \\ 3 & 5 & 8 & 9 \\ 3 & 6 & 8 & 9\end{array}$

File TEST7 - Corresponds to INPUT FILE 2 for the TEMAC Sample Problem, see Table 9 of Ref. 3 .

\begin{tabular}{|c|c|c|c|c|c|c|c|c|c|}
\hline Size & Bas & Eve & i & Set & & & & & \\
\hline$\overline{8}$ & 1 & 2 & 6 & 7 & 10 & 13 & 14 & 16 & \\
\hline 8 & 1 & 2 & 6 & 7 & 10 & 13 & 15 & 16 & \\
\hline 8 & 1 & 2 & 6 & 8 & 10 & 13 & 14 & 16 & \\
\hline 8 & 1 & 2 & 3 & 7 & 10 & 13 & 14 & 16 & \\
\hline 8 & 1 & 2 & 4 & 7 & 10 & 13 & 14 & 16 & \\
\hline 8 & 1 & 2 & 5 & 7 & 10 & 13 & 14 & 16 & \\
\hline 8 & 1 & 2 & 6 & 7 & 9 & 13 & 14 & 1 & \\
\hline 8 & 1 & 2 & 6 & 7 & 9 & 13 & 15 & 16 & \\
\hline 8 & 1 & 2 & 6 & 8 & 9 & 13 & 14 & 16 & \\
\hline 8 & 1 & 2 & 3 & 7 & 9 & 13 & 14 & 16 & \\
\hline 8 & 1 & 2 & 4 & 7 & 9 & 13 & 14 & 16 & \\
\hline 8 & 1 & 2 & 5 & 7 & 9 & 13 & 14 & 16 & \\
\hline 9 & 1 & 2 & 6 & 7 & 11 & 12 & 13 & 14 & 16 \\
\hline 9 & 1 & 2 & 6 & 7 & 11 & 12 & 13 & 15 & 16 \\
\hline 9 & 1 & 2 & 6 & 8 & 11 & 12 & 13 & 14 & 16 \\
\hline 9 & 1 & 2 & 3 & 7 & 11 & 12 & 13 & 14 & 16 \\
\hline 9 & 1 & 2 & 4 & 7 & 11 & 12 & 1 & 14 & 16 \\
\hline & 1 & 2 & 5 & 7 & 11 & 12 & 13 & 14 & \\
\hline
\end{tabular}




\section{B.2 Independent Probability Data}

File PTEST5 - Corresponds to the data used to quantify the noncoherent problem Base illustrated in Figures 3.6 and 3.8 of Ref. 1 .

\section{Event Probability}

$\begin{array}{ll}1 & .1 \\ 2 & .2 \\ 3 & .3 \\ 4 & .4 \\ 5 & .5\end{array}$

File PTEST6 - Corresponds to the data used to quantify the problem der icted in Figure 9 of the User's Manual (Ref. 2). A hand calculation based on this data is included as Appendix $C$ to this report.

Base

Event Probability

$\begin{array}{ll}1 & .1 \\ 2 & .2 \\ 3 & .3 \\ 4 & .4 \\ 5 & .5 \\ 6 & .6 \\ 7 & .7 \\ 8 & .8 \\ 9 & .9\end{array}$

File PTEST7 - Corresponds to INPUT FILE 3 for the TEMAC Sample Problem, see Table 10 of Ref. 3. Note, initiating event probabilities have been decreased by one order of magnitude to avoid probabilities greater than one in the SIGPI input. SIGPI output bounds should correspondingly be increased by one order of magnitude in making comparisons

Base to TEMAC.

Event Probability

$\begin{array}{ll}1 & .05 \\ 2 & .0833 \\ 3 & .00323 \\ 4 & .00266 \\ 5 & .00266 \\ 6 & .1 \\ 7 & .0484 \\ 8 & .016 \\ 9 & .07 \\ 10 & .08 \\ 11 & .24 \\ 12 & .01 \\ 13 & .9 \\ 14 & .0484 \\ 15 & .016 \\ 16 & .01\end{array}$




\section{APPENDIX C - HAND CALCULATION FOR TEST RUN 6}

Test run 6 corresponds to the problem depicted in Figure 9, page 37 of the SIGPI User's Manual [2]. A copy of this figure is reproduced on the next page. The seven original cut stes involve no compliment events. The problem is run assumming independent base events, and the probabilities specified in the PTEST6 file are (in the nomenclature of User's Manual Figure 9):

$$
\begin{aligned}
& \text { PC1 }=0.1, \\
& \text { PC2 }=0.2, \\
& \text { PC3 }=0.3, \\
& \text { PC4 }=0.4, \\
& \text { PC5 }=0.5, \\
& \text { PC6 }=0.6, \\
& \text { PC7 }=0.7, \\
& \text { PC8 }=0.8, \\
& \text { PC9 }=0.9 .
\end{aligned}
$$

The exact solution was first obtained using the expressions for the five disjoint sets resolved in Figure 9 of the User's Manual [2]:

$$
\begin{aligned}
& D P-1 A 1=P C 1 * P C 2 *[1-(1-P C 3)(1-P C 4)] \quad=0.0116 \\
& \begin{aligned}
D P-1 A 2=P C 1 *(1-P C 2) * P C 3 * P C 4 \quad \text { SUBTOTAL } & =0.0096 \\
& =0.0212
\end{aligned} \\
& D P-1 B 1=P C 1 * P C 7 *[1-(1-P C 5)(1-P C 5)] \quad=0.056 \\
& D P-1 B 2=P C 1 *[1-(1-P C 5)(1-P C 6)] *(1-P C 7) * P C 8 * P C 9=\frac{0.01728}{0.07328} \\
& \text { SUBTOTAL }=0.07328 \\
& \begin{aligned}
D P-2=(1-P C 1) *[1-(1-P C 5)(1-P C 6)] * P C 8 * P C 9 & =0.5184 \\
\text { TOTAL } & =0.61288
\end{aligned}
\end{aligned}
$$

Next the problem was solved using a spreadsheet at each of the five decomposition levels depicted in Figure 9 of the User's Manual. The spreadsheet results sre included as sheets 25,26 , and 27 of this report.

Because the SIGPI results for this test did not agree with the hand calculation results, subproblems $1 A, 1 B$, and 2 as indicated below were run separately, and resolved by SIGPI with $A C C=2$ (two place accuracy requested). The SIGPI results presented below agree with those calculaied by hand above:

TEST6-1A.DAT:

$\begin{array}{llll}3 & 1 & 3 & 4 \\ 3 & 1 & 2 & 4 \\ 3 & 1 & 2 & 3\end{array}$

\begin{tabular}{llcll}
\multicolumn{5}{l}{ TEST6-1B.DAT: } \\
3 & 1 & 5 & 7 & \\
3 & 1 & 6 & 7 & \\
4 & 1 & 5 & 8 & 9 \\
4 & 1 & 6 & 8 & 9
\end{tabular}

TEST6-2.DAT:

$\begin{array}{lllll}4 & -1 & 5 & 8 & 9 \\ 4 & -1 & 6 & 8 & 9\end{array}$

SIGPI Results:

$D P=0.0212 \quad D P=0.07328 \quad D P=0.0 .5184$

The reason for SIGPI calculating $U B=0.5980$ and $L B=0.5964$ for the overall TEST6 has not yet been det lined. 


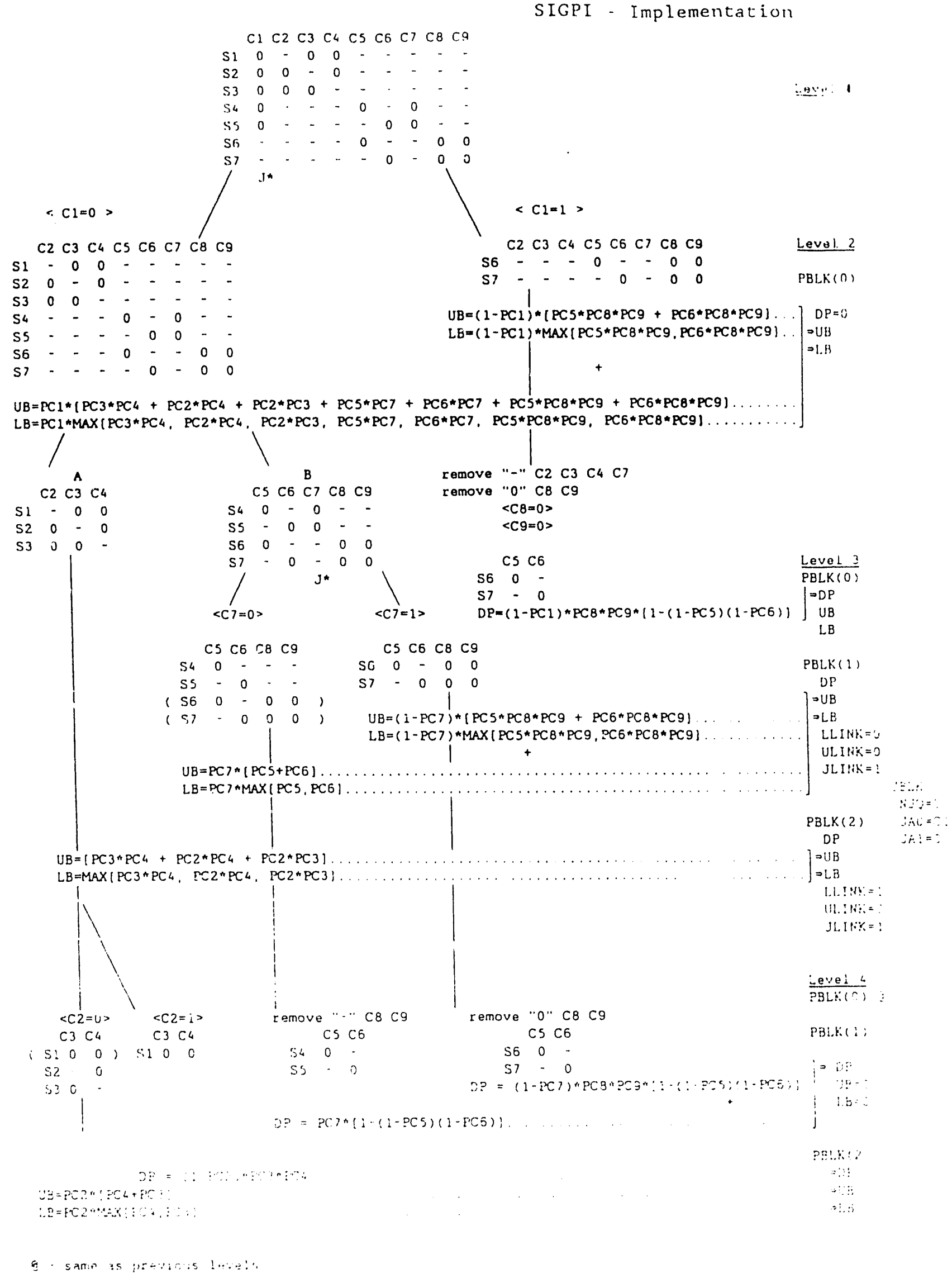


Level 1

\begin{tabular}{|c|c|c|c|c|c|c|c|c|c|c|}
\hline set & Cl & C2 & C3 & C4 & C5 & c6 & C7 & C8 & C9 & \\
\hline S1 & 0.1 & 1 & 0.3 & 0.4 & 1 & 1 & 1 & 1 & 1 & 0.012 \\
\hline s2 & 0.1 & 0.2 & 1 & 0.4 & 1 & 1 & 1 & 1 & 1 & 0.008 \\
\hline s3 & 0.1 & 0.2 & 0.3 & 1 & 1 & 1 & 1 & 1 & 1 & 0.006 \\
\hline S4 & 0.1 & 1 & 1 & 1 & 0.5 & 1 & 0.7 & 1 & 1 & 0.035 \\
\hline S5 & 0.1 & 1 & 1 & 1 & 1 & 0.6 & 0.7 & 1 & 1 & 0.042 \\
\hline S6 & 1 & 1 & 1 & 1 & 0.5 & 1 & 1 & 0.8 & 0.9 & 0.36 \\
\hline S7 & 1 & 1 & 1 & 1 & 1 & 0.6 & 1 & 0.8 & 0.9 & 0.43 \\
\hline & & & & & & & \multicolumn{3}{|c|}{ 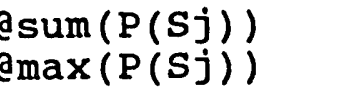 } & 0.43 \\
\hline
\end{tabular}

Level 2

\begin{tabular}{|c|c|c|c|c|c|c|c|c|c|c|c|}
\hline \multirow{8}{*}{$\underset{1}{\text { Subprob }}$} & set & Cl & C2 & C3 & C4 & $\mathrm{C} 5$ & C6 & C7 & C8 & $\mathrm{C} 9$ & \\
\hline & S1 & 0.1 & 1 & 0.3 & 0.4 & 1 & 1 & 1 & 1 & 1 & 0.0120 \\
\hline & 52 & 0.1 & 0.2 & 1 & 0.4 & 1 & 1 & 1 & 1 & 1 & 0.0080 \\
\hline & S3 & 0.1 & 0.2 & 0.3 & 1 & 1 & 1 & 1 & 1 & 1 & 0.0060 \\
\hline & S4 & 0.1 & 1 & 1 & 1 & 0.5 & 1 & 0.7 & 1 & 1 & 0.0350 \\
\hline & S5 & 0.1 & 1 & 1 & 1 & 1 & 0.6 & 0.7 & 1 & 1 & 0.0420 \\
\hline & s6 & 0.1 & 1 & 1 & 1 & 0.5 & 1 & 1 & 0.8 & 0.9 & 0.0360 \\
\hline & S7 & 0.1 & 1 & 1 & 1 & 1 & 0.6 & 1 & 0.8 & 0.9 & 0.0432 \\
\hline
\end{tabular}

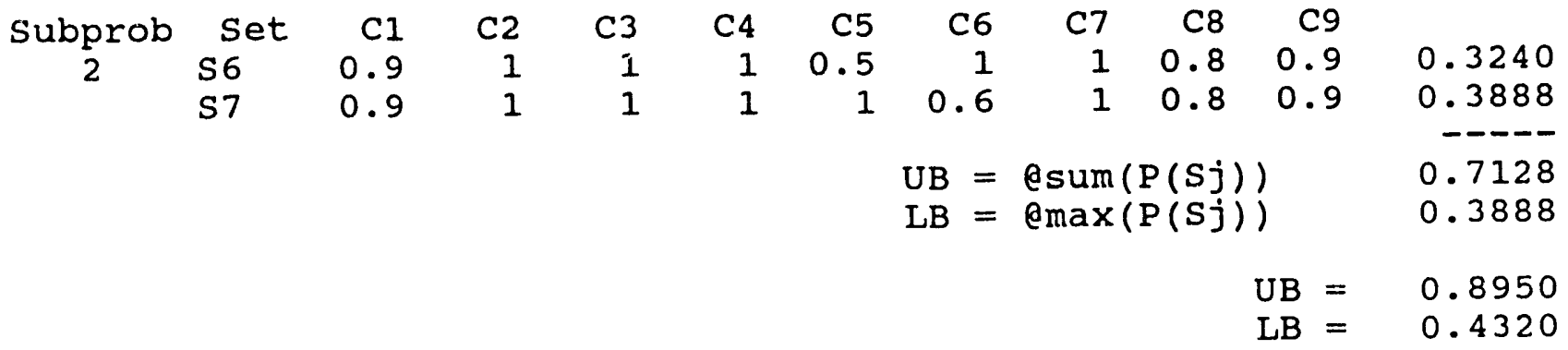


Level 3

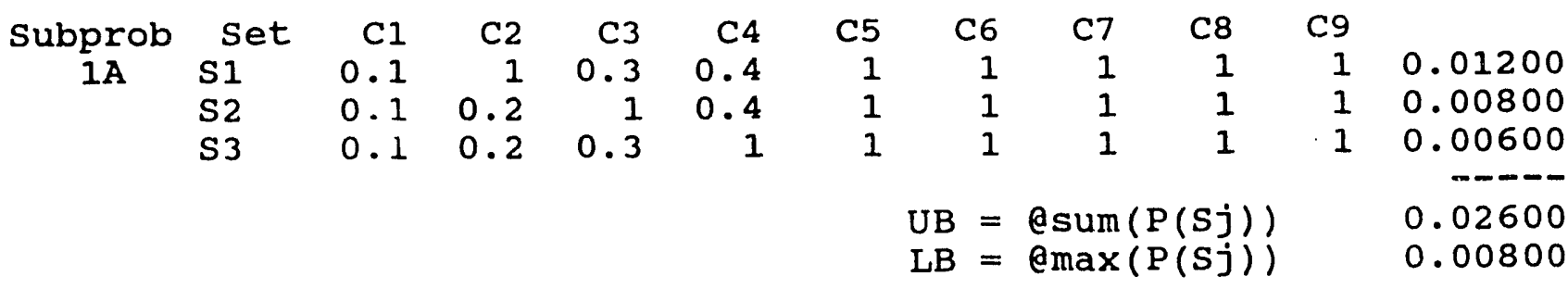

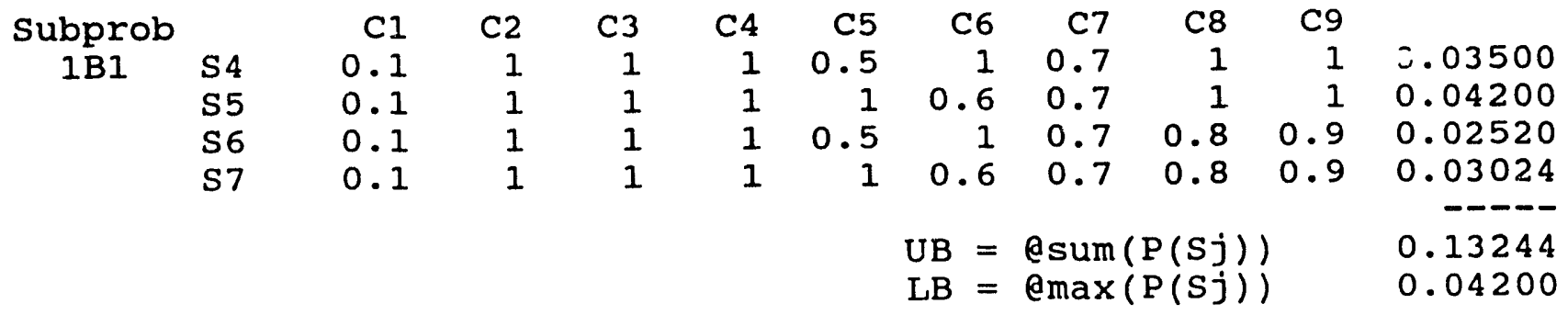

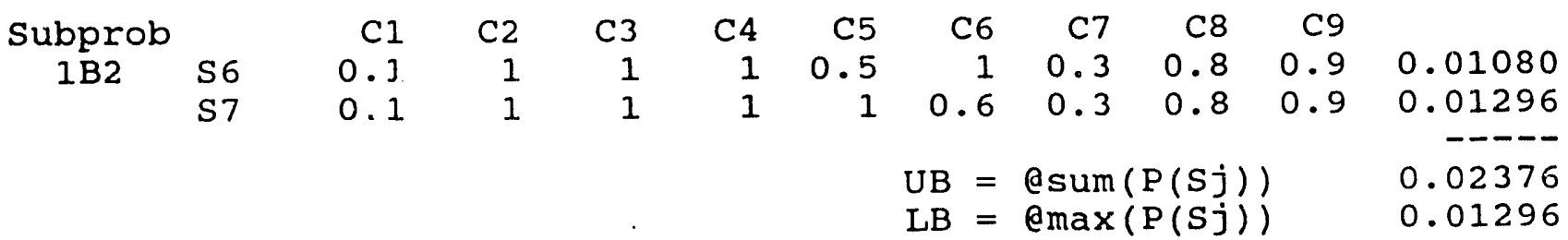

$\begin{array}{rlrrrrrrrrrr}\text { Subprob } & & \text { C1 } & \text { C2 } & \text { C3 } & \text { C4 } & \text { C5 } & \text { C6 } & \text { C7 } & C 8 & \text { C9 } & \\ 2 & \text { S6 } & 0.9 & 1 & 1 & 1 & 0.5 & 1 & 1 & 0.8 & 0.9 & 0.32400 \\ & \text { S7 } & 0.9 & 1 & 1 & 1 & 1 & 0.6 & 1 & 0.8 & 0.9 & 0.38880 \\ & \text { S60r7 } & 0.9 & 1 & 1 & 1 & -0.5 & 0.6 & 1 & 0.8 & 0.9 & -0.19440 \\ & & & & & & & & & & \text { DP }= & 0.51840 \\ & & & & & & & & & & & \\ & & & & & & & & & \text { UB }= & 0.70060 \\ & & & & & & & & & & \text { LB }= & 0.58136\end{array}$


Level 4

Subprob 1 A 1

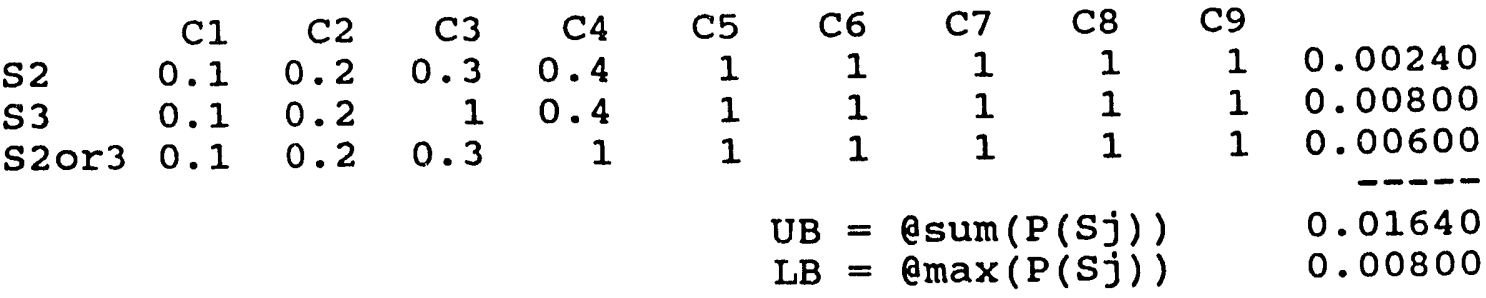

Subprob 1 A 2

$\begin{array}{rrrrrr} & C 1 & C 2 & C 3 & C 4 & C 5 \\ \text { S1 } & 0.1 & 0.8 & 0.3 & 0.4 & 1\end{array}$

$\begin{array}{llll}\text { C6 } & \mathrm{C7} & \mathrm{C} 8 & \mathrm{C} 9\end{array}$

$\begin{array}{rr}1 & 0.00960 \\ D P & 0.00960\end{array}$ Subprob
1B1

$\begin{array}{lrrrrrrrrrr} & C 1 & C 2 & C 3 & C 4 & C 5 & C 6 & C 7 & C 8 & C 9 & \\ \text { S4 } & 0.1 & 1 & 1 & 1 & 0.5 & 1 & 0.7 & 1 & 1 & 0.03500 \\ \text { S5 } & 0.1 & 1 & 1 & 1 & 1 & 0.6 & 0.7 & 1 & 1 & 0.04200 \\ \text { S40r5 } & 0.1 & 1 & 1 & 1 & -0.5 & 0.6 & 0.7 & 1 & 1 & -0.02100 \\ & & & & & & & & & \text { DP }= & 0.05600\end{array}$

Subprob 1B2

$\begin{array}{lrrrrr} & C 1 & C 2 & C 3 & C 4 & C 5 \\ \text { S6 } & 0.1 & 1 & 1 & 1 & 0.5 \\ \text { 57 } & 0.1 & 1 & 1 & 1 & 1 \\ \text { S60r7 } & 0.1 & 1 & 1 & 1 & -0.5\end{array}$

C6 C7 10.3 $\begin{array}{lll}0.6 & 0.3\end{array}$

C8 C9

$\begin{array}{lll}0.8 & 0.9 & 0.01080\end{array}$ s6or7 0.1

$0.6 \quad 0.3$

0.8

0.90 .01296

$0.9-0.00648$

$D P=0.01728$

Subprob

$$
\begin{array}{lrrrrrrrrrr} 
& \text { C1 } & \text { C2 } & \text { C3 } & \text { C4 } & \text { C5 } & \text { C6 } & \text { C7 } & \text { C8 } & \text { C9 } & \\
\text { S6 } & 0.9 & 1 & 1 & 1 & 0.5 & 1 & 1 & 0.8 & 0.9 & 0.32400 \\
\text { S7 } & 0.9 & 1 & 1 & 1 & 1 & 0.6 & 1 & 0.8 & 0.9 & 0.38880 \\
\text { S6or7 } & 0.9 & 1 & 1 & 1 & -0.5 & 0.6 & 1 & 0.8 & 0.9 & -0.19440 \\
& & & & & & & & & \text { DP }= & 0.51840 \\
& & & & & & & & & & \\
& & & & & & & & \text { UB }= & 0.61768 \\
& & & & & & & & & \text { LB }= & 0.60928
\end{array}
$$


Level 5

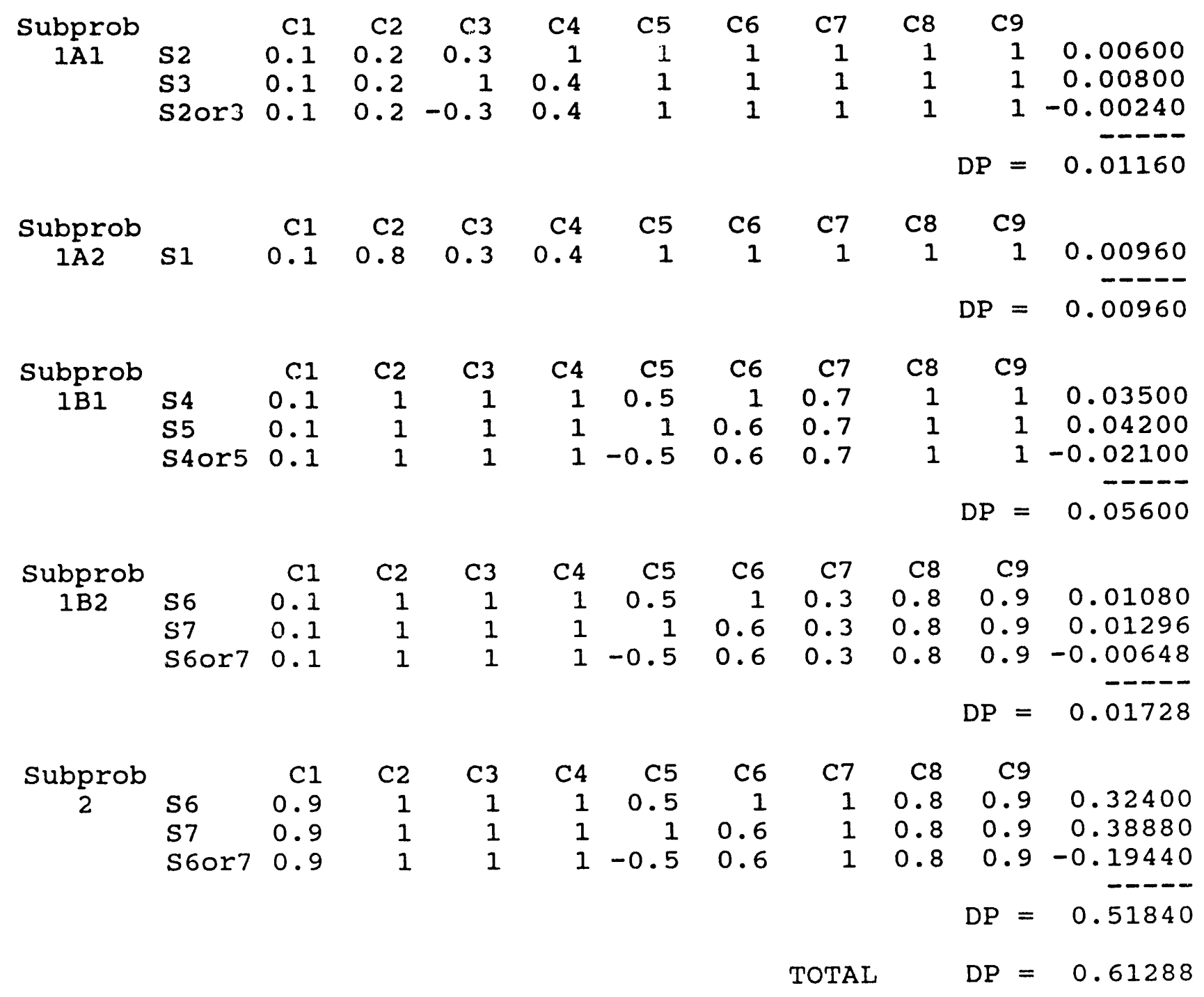




\section{APPENDIX D. PROOF OF ALTERNATIVE LOWER BOUND}

This appendix provides a proof of the assertion that

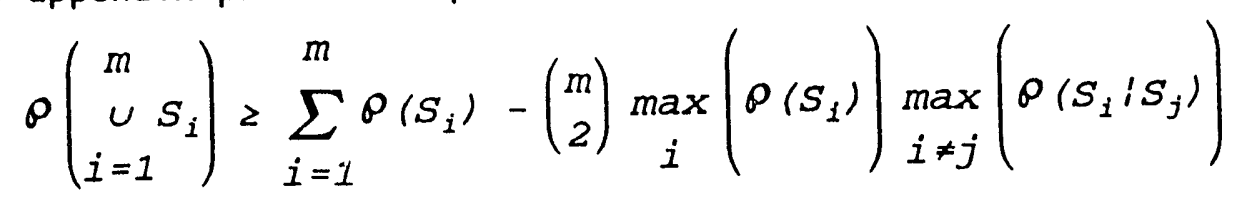

where the $S_{i}$ are Boolean events (simple sets of subproblem $k$ in SIGPI) and $m$ is any integer greater than or equal to 2 ; that is, $i=1,2, \cdots, m$.

For $m=2$, Eq. (1) will hold if

$$
P\left(S_{1} \cup S_{2}\right) \leq P\left(S_{1}\right)+P\left(S_{2}\right)-\max _{i} P\left(S_{i}\right) \max _{i \neq j} P\left(S_{i} i S_{j}\right)
$$

But the left hand side can be expanded to yield

$$
\begin{array}{ll}
P\left(S_{1}\right)+P\left(S_{2}\right) \geq P\left(S_{1}\right)+P\left(S_{2}\right) \\
-P\left(S_{1} \cap S_{2}\right) & -\max P\left(S_{i}\right) \max P\left(S_{1}\left(S_{j}\right)\right.
\end{array}
$$

or

$$
P\left(S_{1}\right) P\left(S_{2} i S_{1}\right) \leq \max P\left(S_{i}\right) \max P\left(S_{i} i S_{j}\right)
$$

which is clearly true. Thus Eq. (1) holds for $m=2$.

Similarly, for $m=3$, Eq. (1) will hold if

$$
\begin{gathered}
P\left(S_{1}\right)+P\left(S_{2}\right)+P\left(S_{3}\right) \geq P\left(S_{1}\right)+P\left(S_{2}\right)+P\left(S_{3}\right) \\
-P\left(S_{1} \cap S_{2}\right)-P\left(S_{1} \cap S_{2}\right)-P\left(S_{2} \cap S_{3}\right) \\
+P\left(S_{1} \cap S_{2} \cap S_{3}\right)
\end{gathered}
$$

or

$$
\begin{aligned}
& P\left(S_{1}\right) P\left(S_{2} i S_{1}\right) \leq 3 \max P\left(S_{i}\right) \max P\left(S_{i} i S_{j}\right) \\
+ & P\left(S_{1}\right) P\left(S_{3} i S_{1}\right) \\
+ & P\left(S_{2}\right) P\left(S_{3} i S_{2}\right) \\
& -P\left(S_{1} \cap S_{2} \cap S_{3}\right)
\end{aligned}
$$

which is clearly true. Thus Eq. (1) holds for $m=3$.

The balance of the proof is by induction. Assume Eq. (1) holds for m-1 Boolean events (simple sets); that is, assume 


$$
P\left(U_{m-1}\right)=\sum_{i=1}^{m-1} \rho\left(S_{i}\right)-\frac{(m-1)(m-2)}{2} \max _{i} \rho\left(S_{i}\right) \max _{i \neq j} \rho\left(S_{i} i S_{j}\right)
$$

where $U_{m-1}$ is used to denote the union of the first m-1 Boolean events:

$$
U_{m-1}=S_{1} \cup S_{2} \cup \cdots \cup S_{m-1}
$$

Given this assumption, Eq. (1) will be proved if it can be shown that

$$
\rho\left(U_{m}\right) \geq \sum_{i=1}^{m} \rho\left(S_{i}\right)-\frac{m(m-1)}{2} \max _{i} P\left(S_{i}\right) \max _{i \neq j} \rho\left(S_{i} i S_{j}\right)
$$

where

$$
U_{m}=U_{m-1} \cup S_{m}=S_{1} \cup S_{2} \cup \cdots \cup S_{m}
$$

By the expression for the union of two events

$$
P\left(U_{m}\right)=P\left(U_{m-1}\right)+P\left(S_{m}\right)-P\left(U_{m-1} \cap S_{m}\right)
$$

Substituting Eq. (11) into Eq. (9), Eq. (1) will be proved if it can be shown that

$$
P\left(U_{m-1}\right)+P\left(S_{m}\right)-P\left(U_{m-1} \cap S_{m}\right) \geq \sum_{i=1}^{m} \rho\left(S_{i}\right)-\frac{m(m-1)}{2} \max _{i} \rho\left(S_{i}\right) \max _{i \neq j} \rho\left(S_{i} i S_{j}\right)
$$

Subtracting Eq. (7) from Eq. (12), Eq. (1) will be proved if it can be shown that

$$
-\rho\left(U_{m-1} \cap S_{m}\right) \geq-(m-1) \max _{i} \rho\left(S_{i}\right) \max _{i \neq j} \rho\left(S_{i} i S_{j}\right)
$$

or

$$
\rho\left(U_{m-1} \cap S_{m}\right) \leq(m-1) \max _{i} \rho\left(S_{i}\right) \max _{i \neq j} \mathcal{i}\left(S_{i} i S_{j}\right)
$$

or

$$
P\left(S_{m}\right) P\left(U_{m-1} i S_{m}\right) \leq(m-1) \max _{i} P\left(S_{i}\right) \max _{i \neq j} \rho\left(S_{i} i S_{j}\right)
$$


Clearly

$$
P\left(S_{m}\right) \leq \max _{i} \rho\left(S_{i}\right)
$$

So Eq. (1) will be proved if

$$
P\left(U_{m-1} i S_{m}\right) \leq(m-1) \max _{i \neq j} \rho\left(S_{i} i S_{j}\right)
$$

and this is true because

$$
P\left(U_{m-1} i S_{m}\right) \leq \sum_{i=1}^{m-1} \rho\left(S_{i} i S_{m}\right) \leq(m-1) \max _{i \neq j} \rho\left(S_{i} i S_{j}\right)
$$

Q.E.D. 
APPENDIX E. SIGPI CALL TREE

MASKS

SIGPI

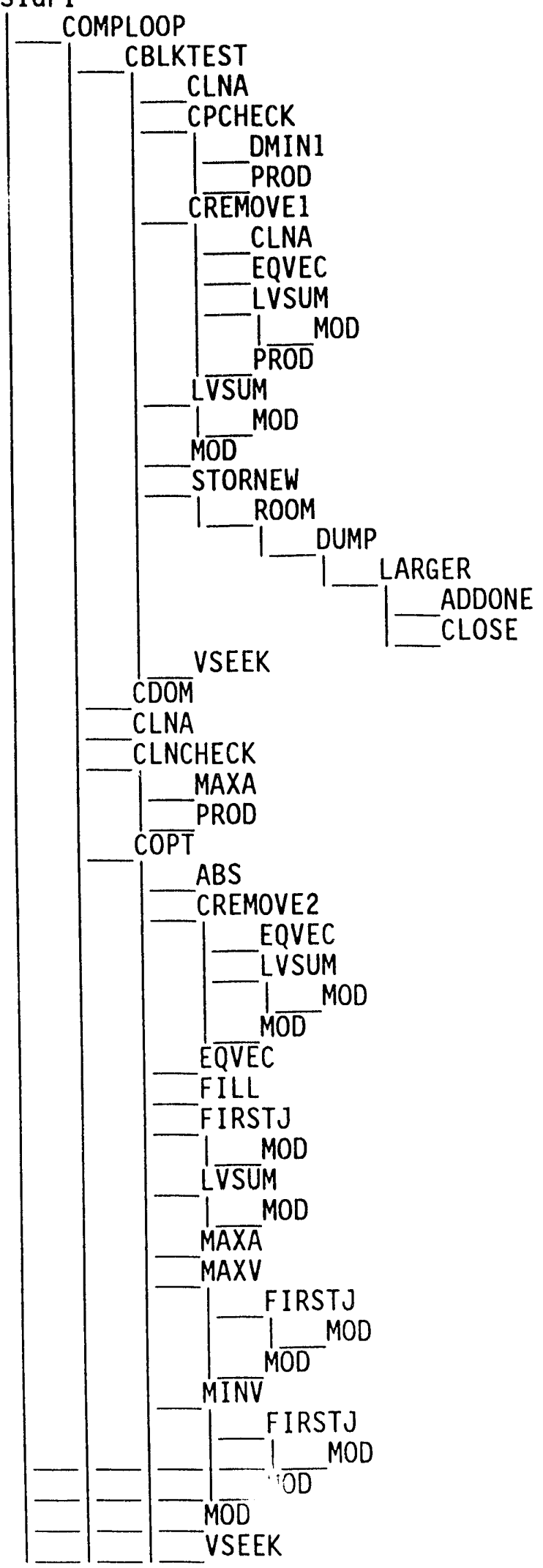




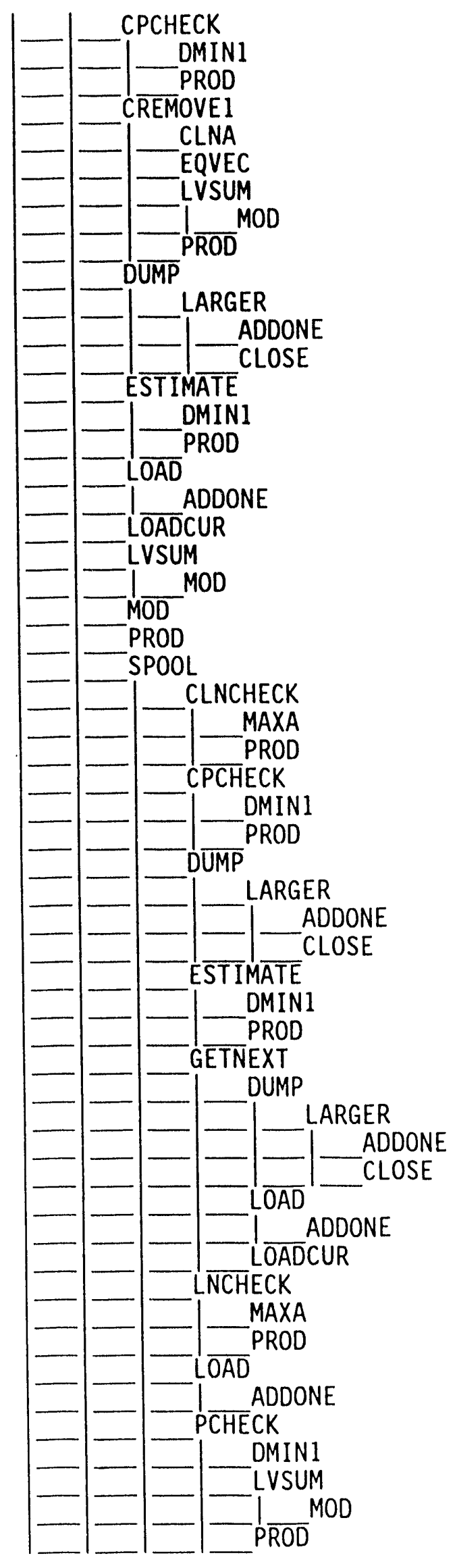




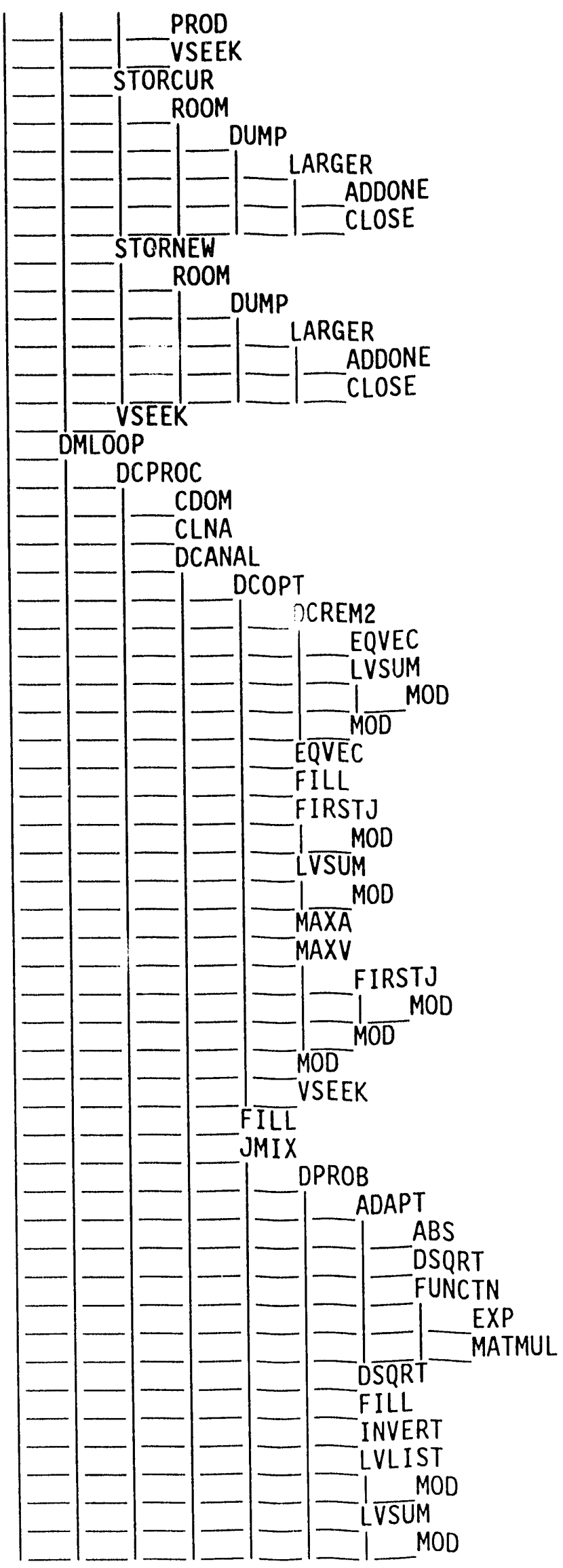




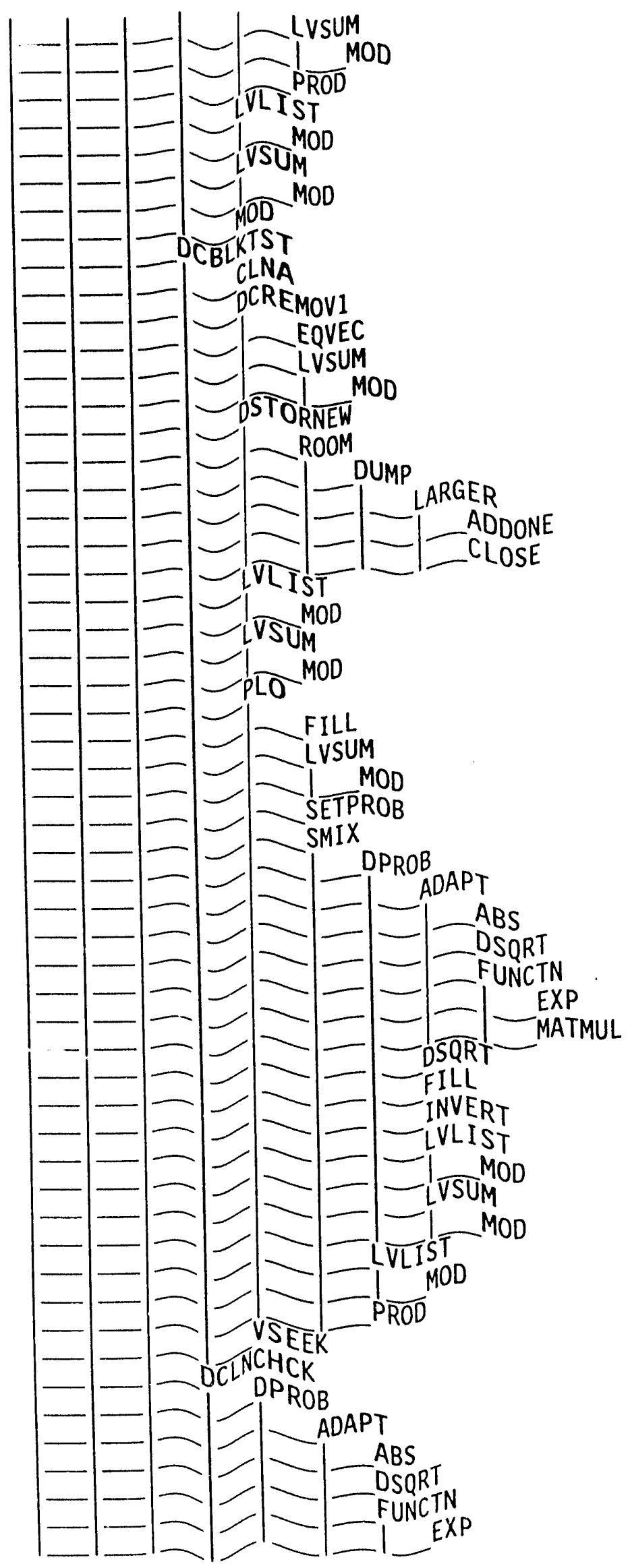




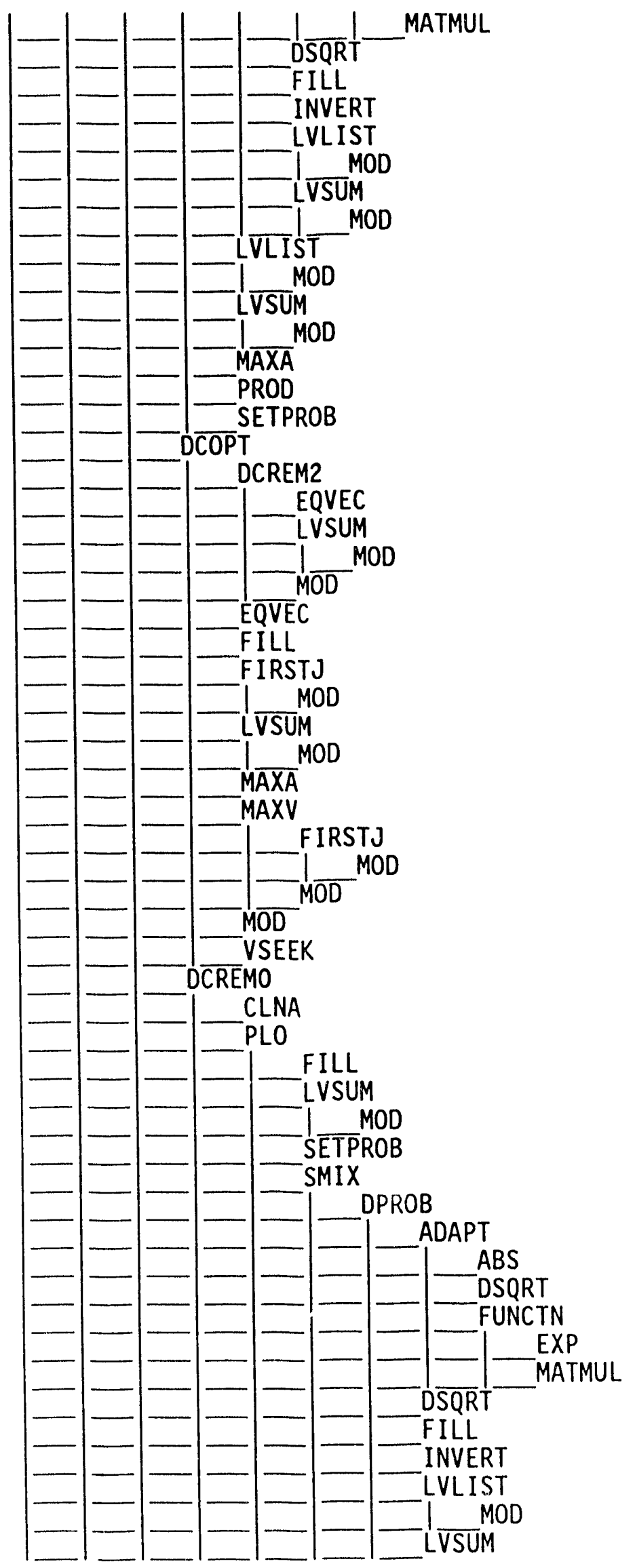




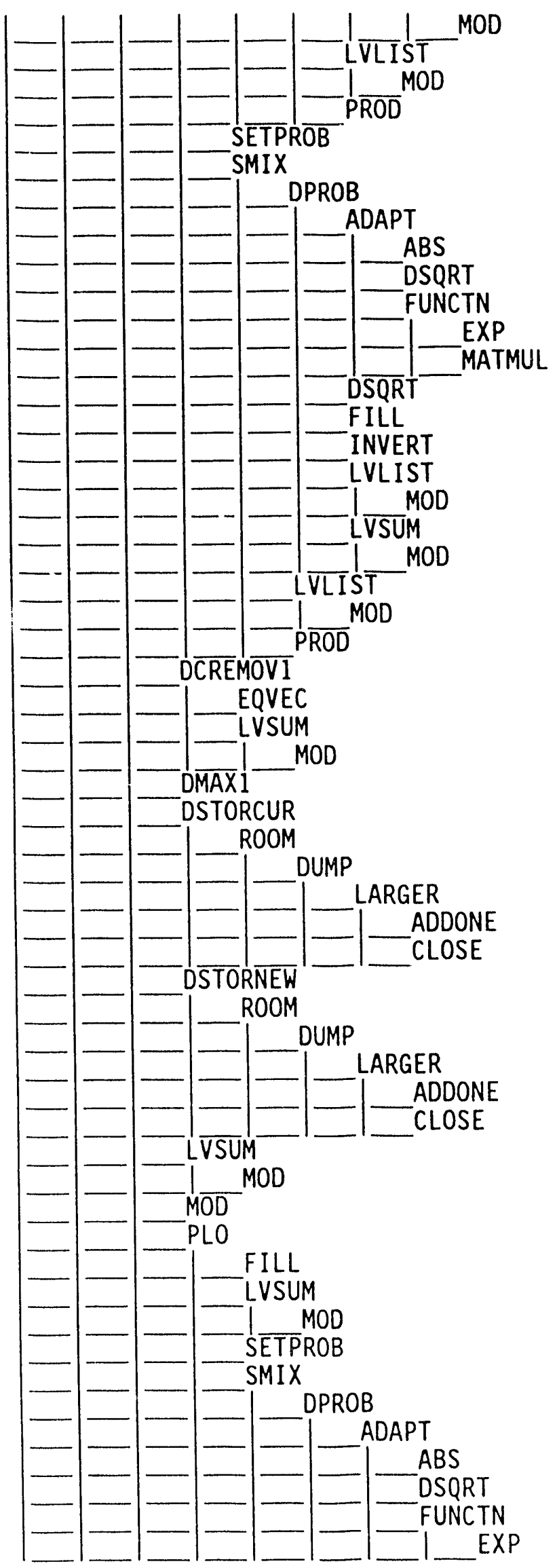




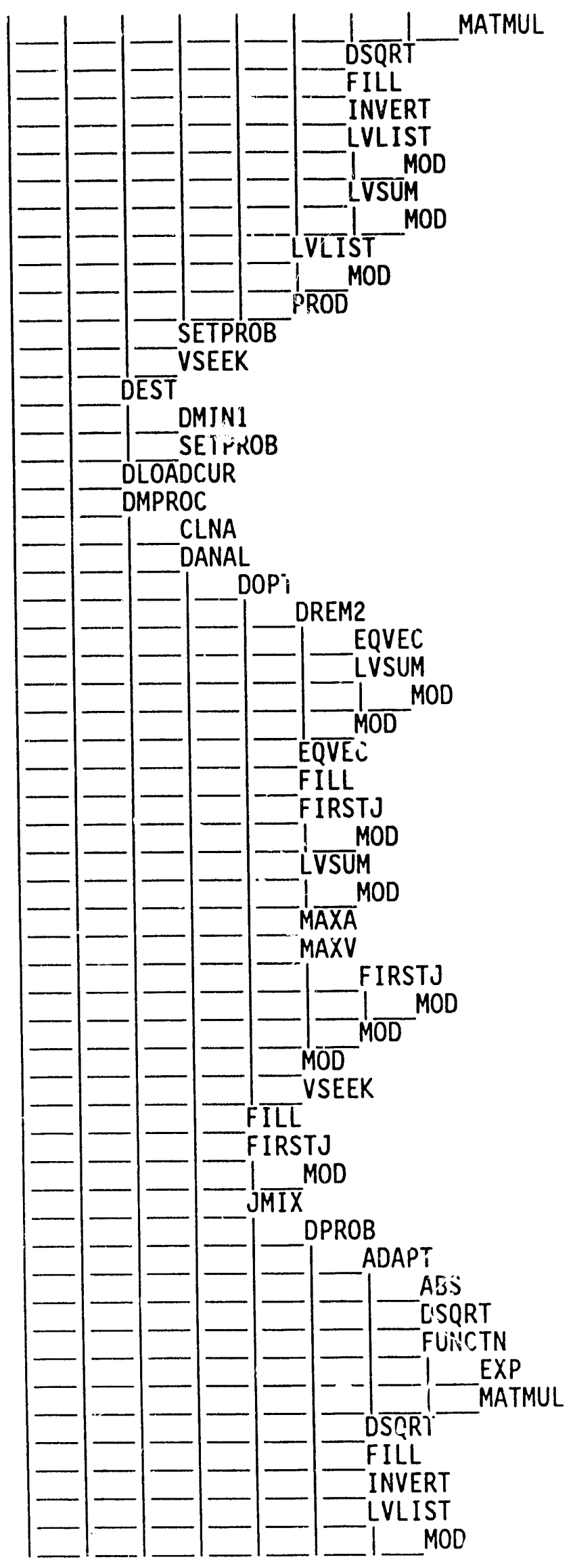




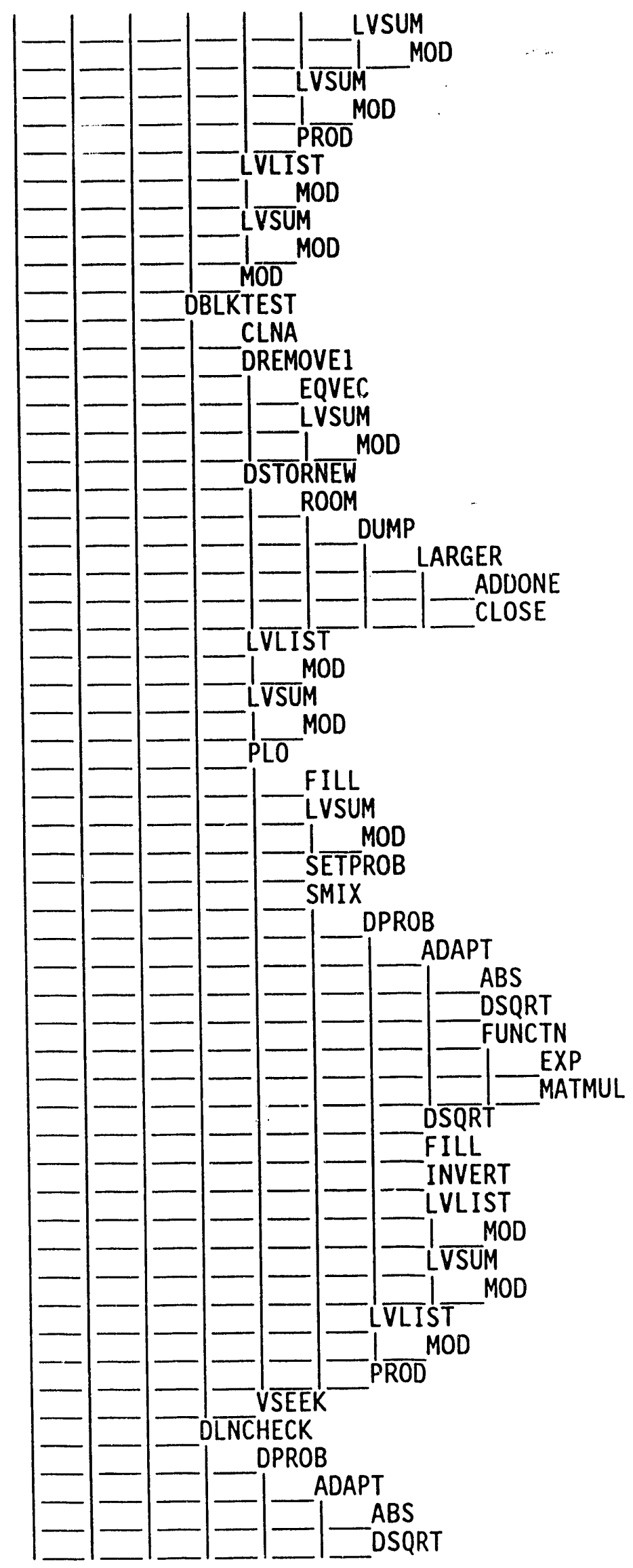




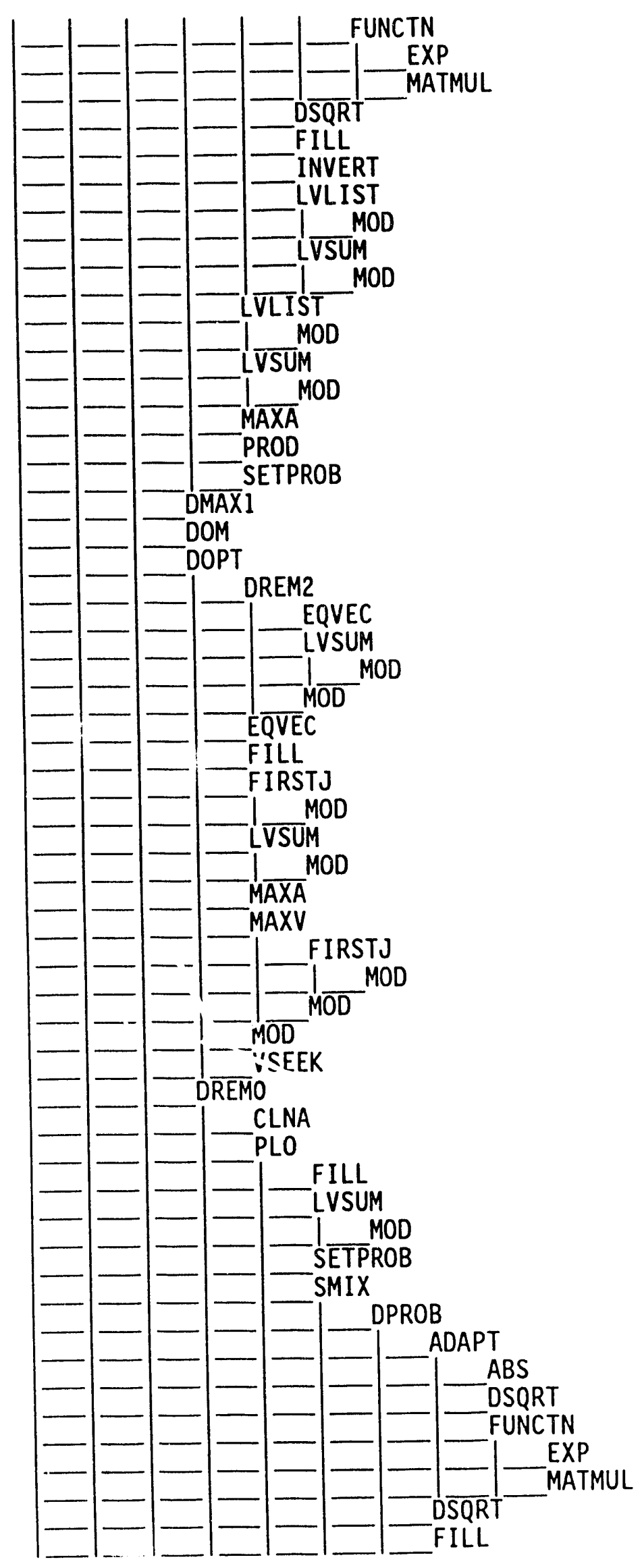




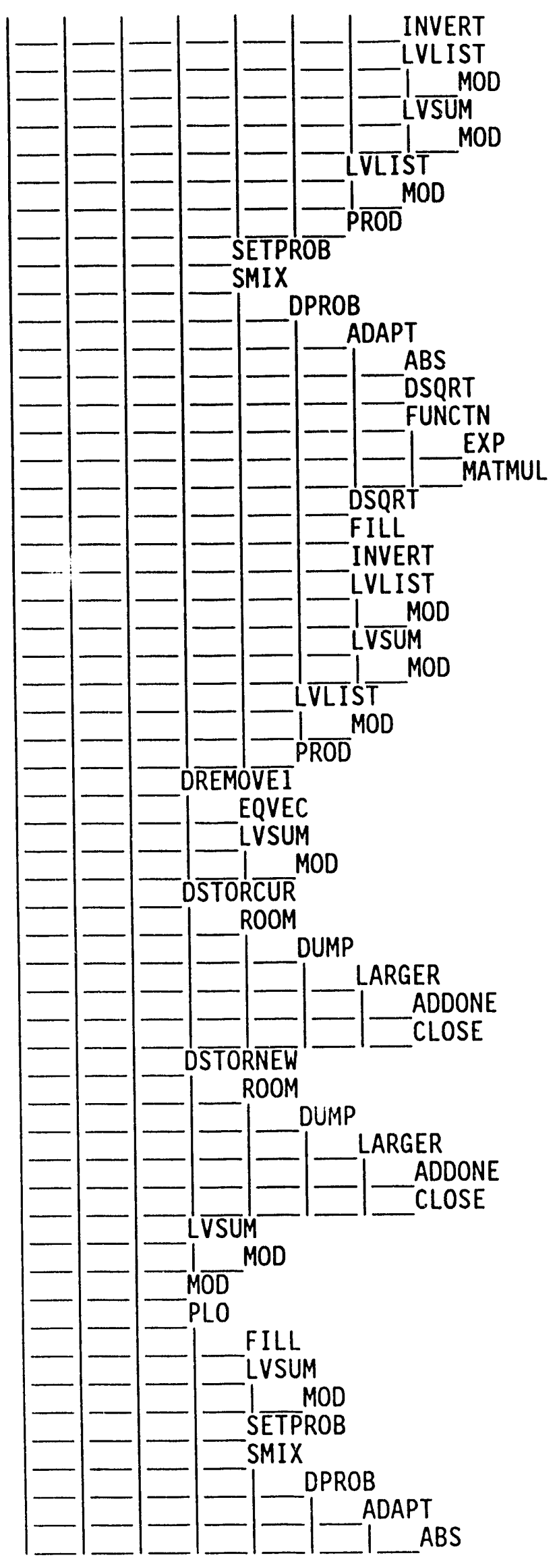




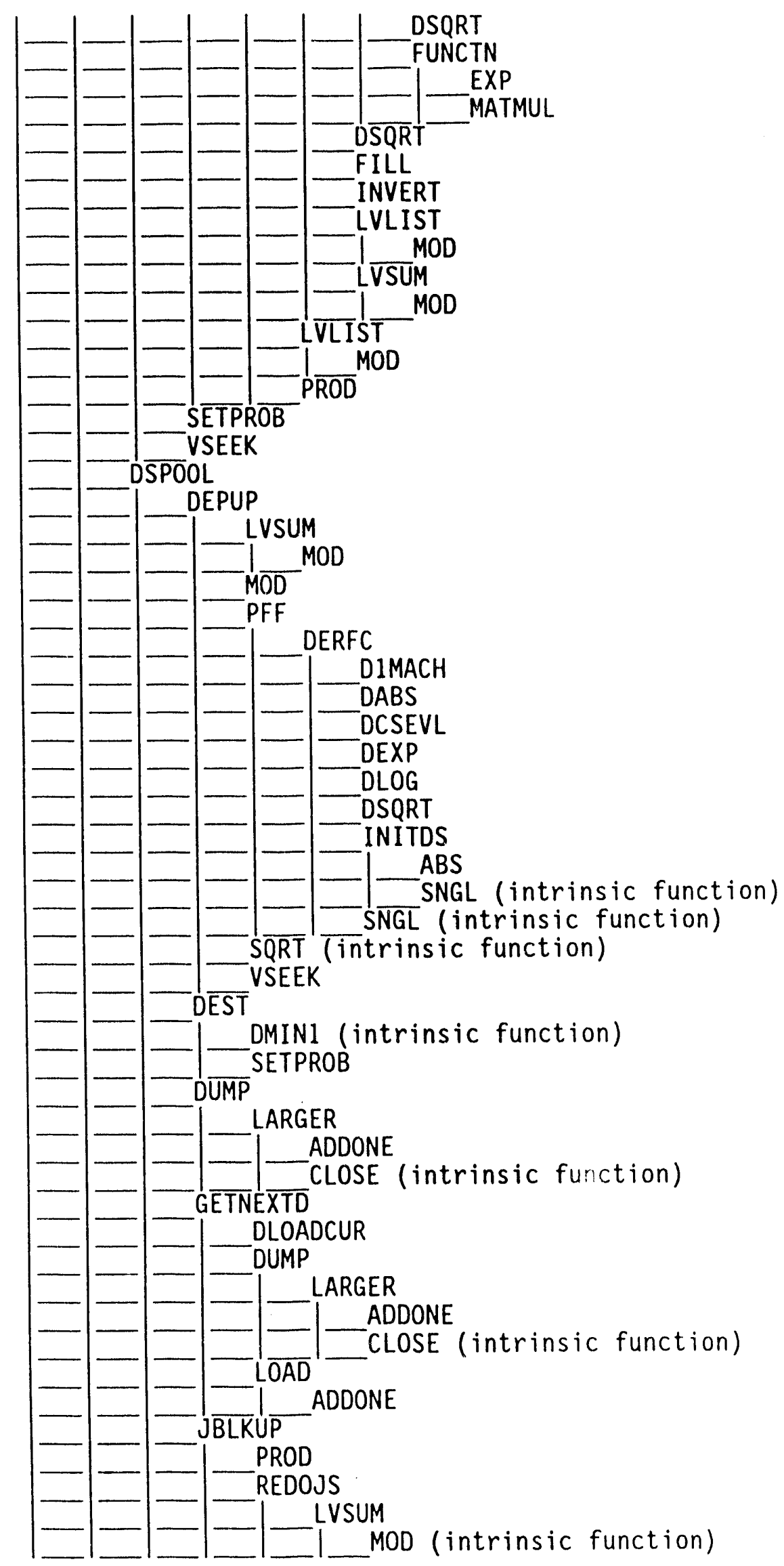




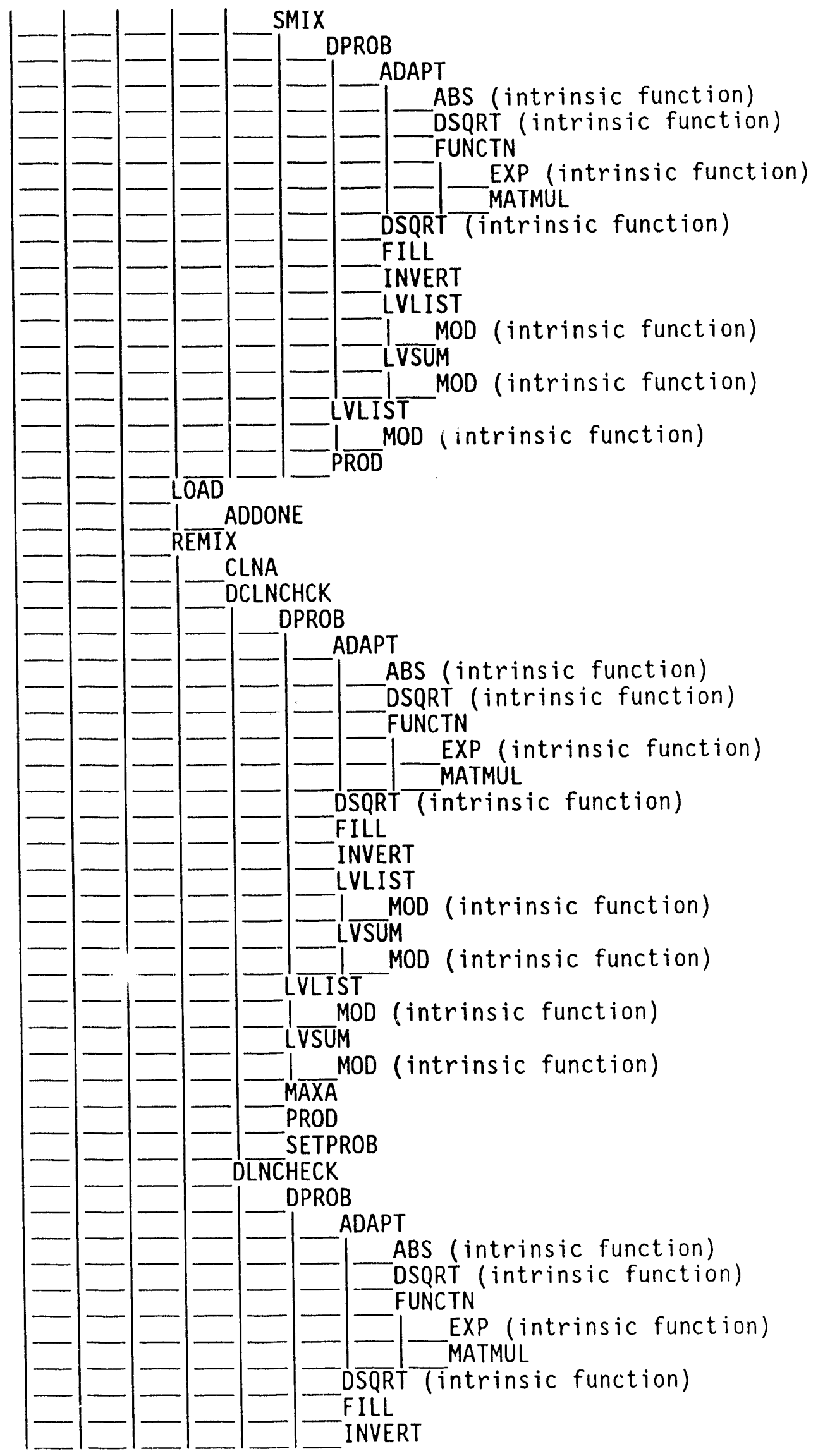




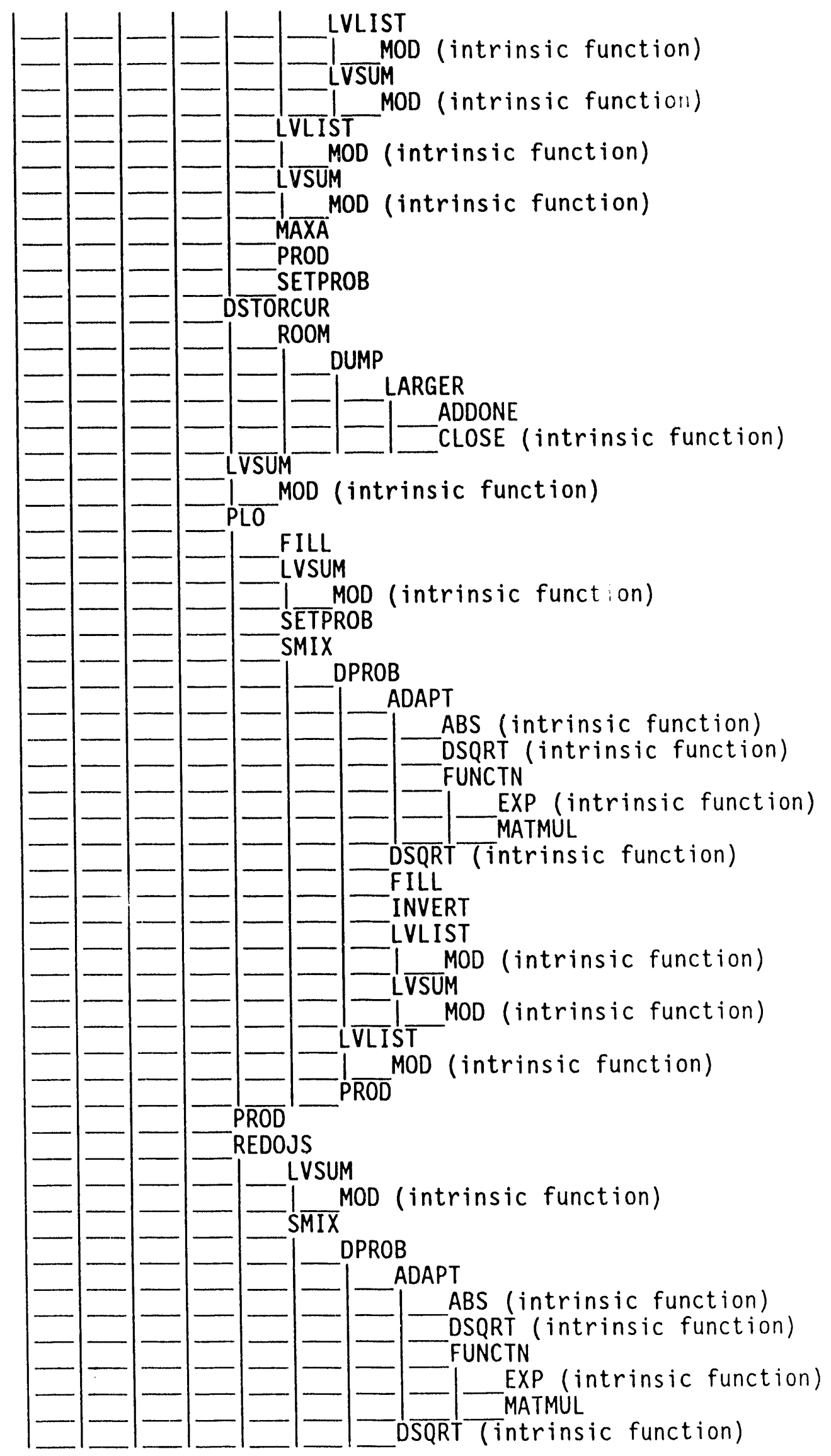




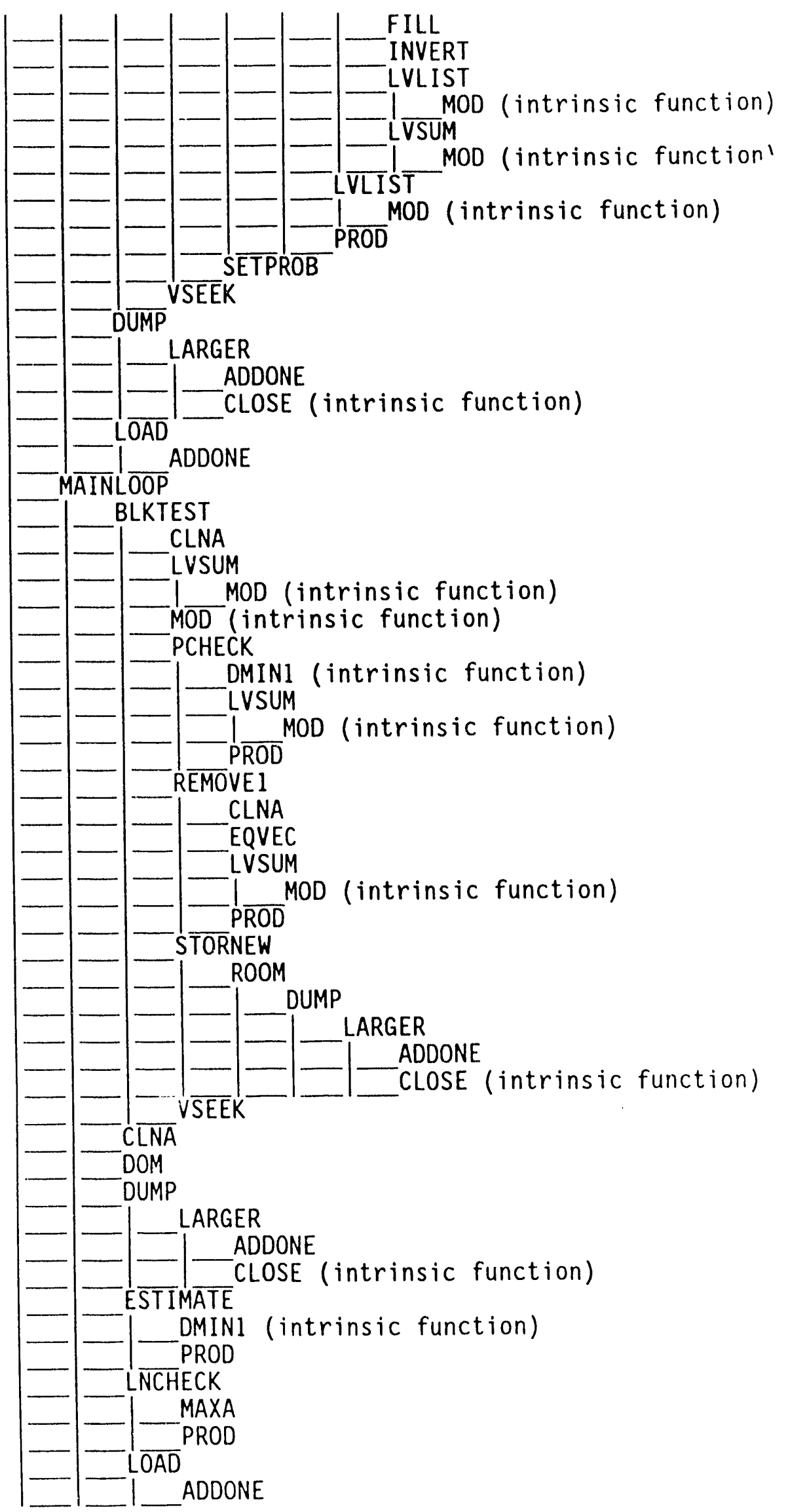




$$
\begin{aligned}
& \text { (intrinsic function) } \\
& \hline \\
& \hline
\end{aligned}
$$




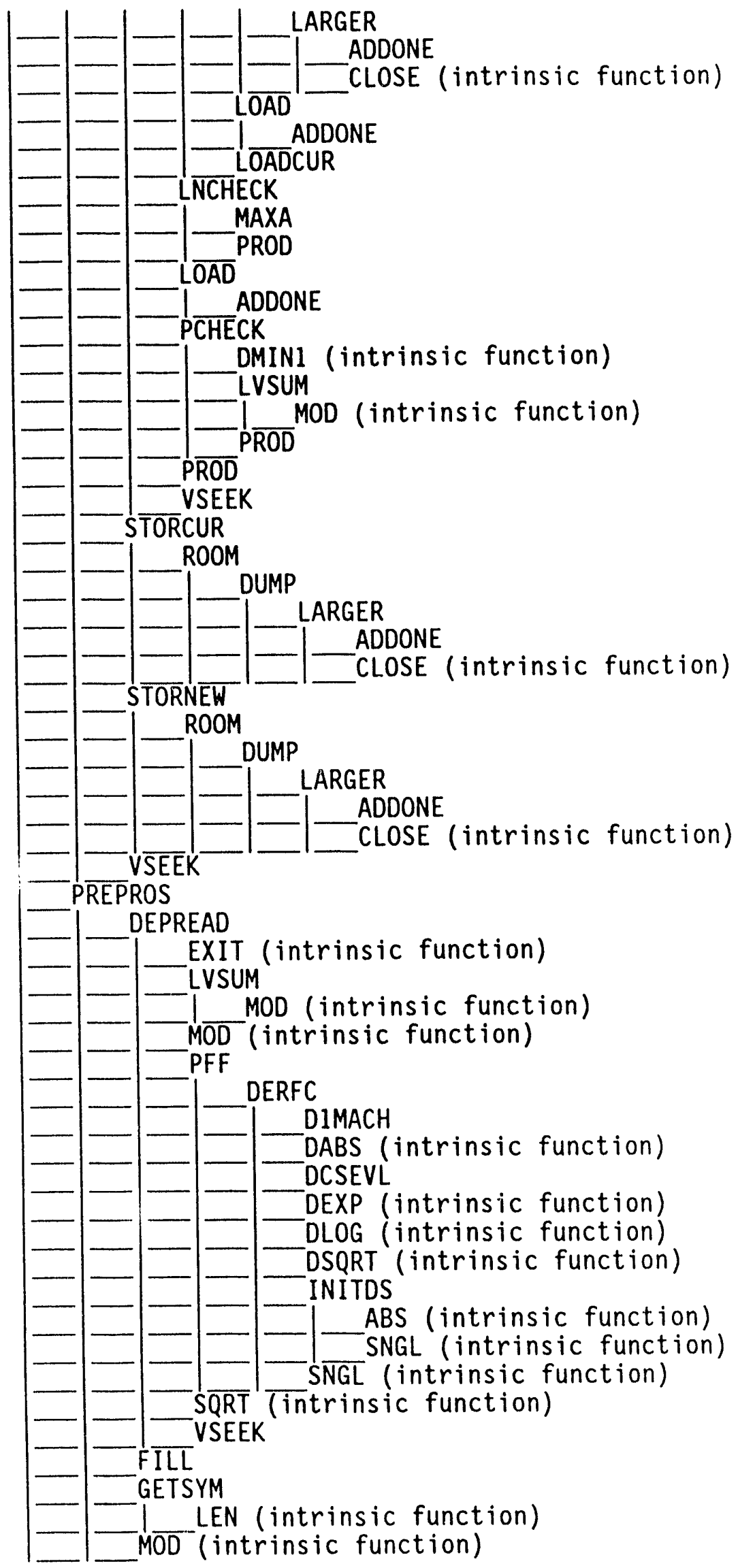




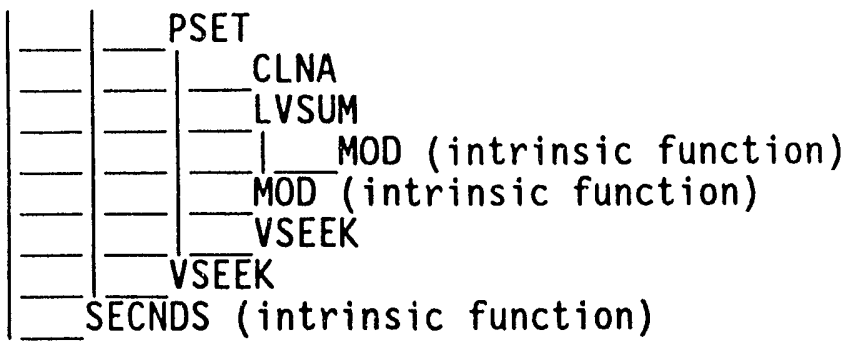



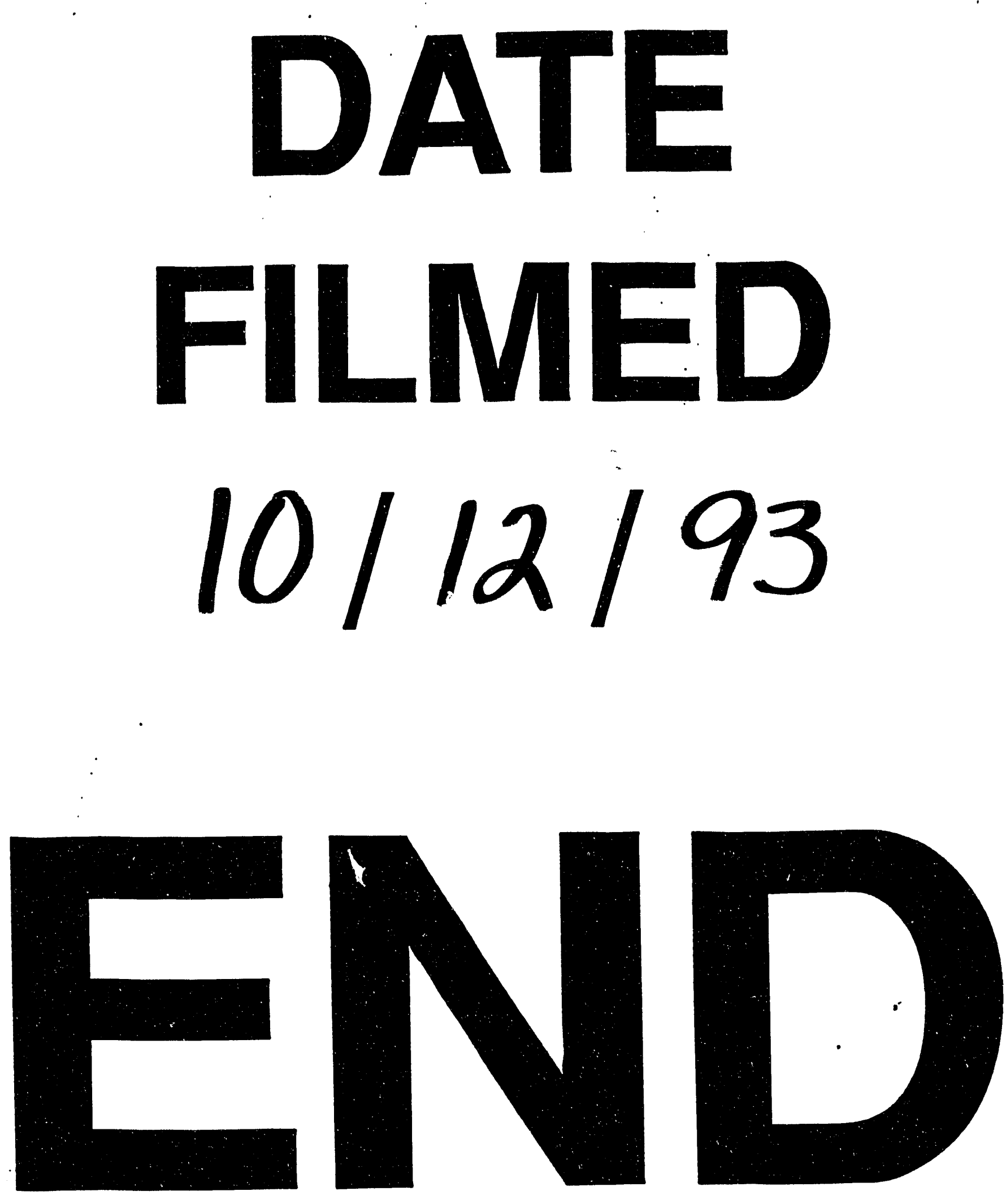
